\title{
Variabilidad genética en géneros de ciervos neotropicales (Mammalia: Cervidae) según loci microsatelitales
}

\author{
Manuel Ruiz-García ${ }^{1 *}$, María Martinez-Agüero ${ }^{1}$, Diana Álvarez ${ }^{1} \&$ Simon Goodman $^{2}$ \\ 1. Unidad de Genética (Genética de Poblaciones-Biología Evolutiva), Departamento de Biología, Facultad de Ciencias, \\ Pontificia Universidad Javeriana, Cra 7A No 43-82, Bogotá DC. Colombia; mruiz@javeriana.edu.co; \\ mruizgar@yahoo.es \\ 2. Institute of Cell, Animal and Population Biology, University of Edinburgh, United Kingdom. \\ * Correspondence
}

Recibido 14-X-2007. Corregido 05-IV-2009. Aceptado 07-V-2009.

\begin{abstract}
Genetic variability in Neotropical deer genera (Mammalia: Cervidae) according to DNA microsatellite loci. Species conservation programs are highly based on analyses of population genetics. We compared eight Neotropical Cervidae (Mazama americana, M. gouzaoubira, M. rufina, Odocoileus virginianus, Hippocamelus antisensis, Pudu mephistopholes, Ozotoceros bezoarticus and Blastoceros dichotomus) and some European and Asian Cervidae (Cervus elaphus, C. nippon, Capreolus capreolus, C. pygargus and Dama dama). The European species C. elaphus was our standard for a high degree of genetic variability: we used a Scottish population originated in the mix of diverse Western European subspecies. On the contrary, Cervus nippon (a population from Scotland with a founder effect) was our standard for a depauperated population. The M. americana, M. gouzaoubira and $O$. virginianus samples had high diversity values close to our $C$. elaphus population $(\mathrm{H}=0.64,0.70$ and 0.61 , respectively), while $M$. rufina was very low, close to C. nippon. Several sample sets of Mazama and Odocoileus yielded a homozygote excess, probably due to the Wahlund (subdivison) effect. There was no evidence of recent bottleneck events. Rev. Biol. Trop. 57 (3): 879-904. Epub 2009 September 30.
\end{abstract}

Key words: Neotropical Cervidae, Mazama, Odocoileus, DNA microsatellites, population genetics.

El presente estudio, complementario al de Ruiz-García et al. (2007), se fundamenta en la determinación y comparación de los niveles de diversidad génica entre diversas especies de cérvidos neotropicales respecto a algunas especies de cérvidos europeos y asiáticos. Este es el primer estudio donde se reportan niveles de diversidad genética en cérvidos neotropicales mediante marcadores microsatélites hipervariables. Por eso, únicamente se pueden efectuar comparaciones con algunas especies de ciervos europeos y asiáticos ya que son los únicos cérvidos que han sido estudiados desde la misma perspectiva molecular (ver Goodman et al. 2001).
En el ámbito de la genética conservacionista se asume que cuanto menor sea el tamaño efectivo de una población, menor será, también, la diversidad genética de la misma $\mathrm{y}$, por ende, tendrá menores posibilidades de poder responder adaptativamente ante cualquier tipo de cambio ambiental (Ruiz-Garcia 2001). Para llevar a cabo esta tarea, se obtuvieron 71 muestras de ciervos neotropicales. Las muestras provienen de diferentes regiones geográficas de Latinoamérica y pertenecen a ocho especies diferentes de los tres grupos tradicionalmente establecidos. Estas especies son: Odocoileus virginianus, Ozotoceros bezoarticus y Blastocerus dichotomus (alto porte, cuernos 
ramificados), Hippocamelus antisensis (mediano porte, cuernos bifurcados), Mazama americana, Mazama gouazoubira, Mazama rufina, у Pudu mephistopheles (pequeño porte, cuernos no ramificados). Adicionalmente, y como punto de comparación, se reunieron muestras de Cervus elaphus (ciervo rojo europeo) de una población escocesa (Gran Bretaña) proveniente, de múltiples reintroducciones de estos ciervos a partir de diversas áreas de la Europa continental. Esta especie presenta multitud de poblaciones y subespecies, en Europa, que han sido reconocidas como diferentes a partir de estudios morfológicos, bioquímicos y moleculares. Whitehead (1972) reconoció 23 subespecies de Cervus elaphus. Hartl et al. (1995) estudiaron el ADN mitocondrial de Cervus elaphus procedentes de 15 localidades distribuidas por el centro, occidente y sur-este de Europa y descubrieron nueve haplotipos mitocondriales diferentes. La relación entre esos haplotipos fue consistente con la distribución geográfica de las diversas poblaciones analizadas. La distribución geográfica de los haplotipos de los tres linajes principales se corresponden con diversas subespecies morfológicas propuestas por Groves \& Grubb (1987). Lowe \& Gardiner (1974), únicamente reconocieron C. e. elaphus como la única subespecie del norte de Europa en virtud de sus análisis craneométricos. El linaje europeo oriental podría corresponder a la subespecie morfológica C. e. montanus, mientras que el linaje sur-oriental podría corresponder a C. e. maral. Eso nos induce a pensar que la variabilidad genética de las muestras obtenidas en Escocia debería ser muy elevada, ya que podrían representar individuos híbridos de esas diversas subespecies de ciervo rojo en Europa. Por lo tanto, los resultados de esa muestra pueden representar un límite superior en cuanto al nivel de heterocigosis (=diversidad genética) que se encuentran en las poblaciones de cérvidos. También se analizaron muestras de Cervus nippon (sika) procedentes de Escocia. Esta es una especie de origen asiático que se introdujo, por primera vez, en Gran Bretaña en 1860 (Powerscourt 1884), con posteriores reintroducciones hasta, aproximadamente,
1930 (Goodman et al. 2000). Las muestras obtenidas provienen de una población pequeña que pudo sufrir un intenso efecto fundador con la consiguiente pérdida de variabilidad genética (Emmerson \& Tate 1993). Igualmente, Goodman et al. (2001) determinaron la heterocigosis de diversas poblaciones de Cervus nippon en Japón y de poblaciones introducidas en Escocia. Las poblaciones japonesas en las zonas más fragmentadas, como Nagasaki $(\mathrm{H}=0.19)$ y Tanegashima $(\mathrm{H}=0.21)$, presentaron niveles de variabilidad genética inferiores al de las poblaciones con hábitats amplios, tales como Iwate $(\mathrm{H}=0.49)$, Kinkazan $(\mathrm{H}=0.54)$, Shimane $(\mathrm{H}=0.45)$ y Hyogo $(\mathrm{H}=0.60)$. Las cuatro poblaciones de $C$. nippon introducidas en Escocia e Inglaterra presentaron niveles reducidos de heterocigosis (Argyll, $\mathrm{H}=0.13$; Fife, $\mathrm{H}=0.27$; Peebles, $\mathrm{H}=0.38$ y Dorset, $\mathrm{H}=0.21$ ) mostrando evidente depauperación genética por efecto fundador. La pregunta central que nos formulamos en el presente trabajo es la siguiente. ¿Están los niveles de variabilidad genética en diversas especies de cérvidos neotropicales más cercanos a los altos valores esperados del Cervus elaphus en Escocia, probablemente resultado del cruzamiento entre individuos representativos de diversas subespecies?. O, por el contrario, ¿están más cercanos a los niveles reducidos de diversidad génica del Cervus nippon introducido en Gran Bretaña?. Esto es, el nivel reducido de variabilidad genética de C. nippon en las poblaciones japonesas pequeñas, y en las introducidas en Gran Bretaña, puede mostrar un límite inferior, denotando un estado de variabilidad genética pobre para las poblaciones de ciervos neotropicales que estén cercanas a esos valores. Por el contrario, las poblaciones de cérvidos neotropicales que posean niveles de variabilidad genética similares al $C$. elaphus escocés $(\mathrm{H}=0.71)$ pueden considerarse como poseedoras de una diversidad genética elevada. Esos son los niveles de variabilidad genética más reducidos y más elevados que se han encontrado en cérvidos utilizando marcadores microsatélites idénticos a los que se emplearon en el presente estudio. Adicionalmente para tener una perspectiva más 
amplia de la citada cuestión, se consiguieron muestras de ADN de otros cérvidos europeos: C. elaphus de origen italiano, Capreolus capreolus (corzo) procedentes de España y de Italia, y Dama dama (gamo) procedentes, también, de España y de Italia. De forma comparativa, se analizaron algunas muestras del rebeco catalán (Rupycapra pyrenaica), un bóvido silvestre.

Para ello, se aplicaron 16 marcadores hipervariables microsatélites (STRP; Short Tandem Repeat Polimorphisms) diseñados para diferentes especies. Diez de ellos fueron diseñados para bóvidos y están altamente conservados en otros Artiodactyla, como los Cervidae y los Caprinae (Slate et al. 1998). Otros autores (Engel et al. 1996) han mostrado, también, que otro conjunto de 12 microsatélites elaborados para bovinos, siete para caprinos y un par específico de ovinos, son útiles para su aplicación en cérvidos.

También, a partir de los resultados moleculares obtenidos, se realizaron diferentes análisis poblacionales. Entre ellos la estimación de la heterogeneidad genética entre poblaciones de una misma especie y la determinación de posibles cuellos de botella recientes en algunas de las especies analizadas.

\section{MATERIALES Y MÉTODOS}

Análisis molecular: Las especies de cérvidos neotropicales y el número total de ejemplares analizados fueron: 22 muestras de Mazama americana, ocho muestras de Mazama gouazoubira, dos muestras de Mazama rufina, 23 muestras de Odocoileus virginianus, cuatro muestras de Hippocamelus antisensis, dos muestras de Pudu mephistopheles, dos muestras de Ozotoceros bezoarticus, ocho muestras de Blastocerus dichotomus, sumando un número total de 71 individuos. Para las especies europeas y de origen asiático, se estudiaron nueve ejemplares de Cervus elaphus y cinco de Cervus nippon, 26 ejemplares de Capreolus capreolus, cinco ejemplares de Dama dama, más cuatro ejemplares de Capreolus pygargus, sumando un total de 49 ejemplares. Comparativamente, se procesaron, también, muestras de cuatro Rupicapra pyrenaica (Rebeco, Bovidae) procedentes de los Pirineos Catalanes. La descripción del origen de los ejemplares analizados y el tipo empleado de muestra de los cérvidos neotropicales estudiados se encuentra en el Cuadro 1. Para la interpretación de los análisis se consideró dos especies Europeas como referencias: la especie Cervus elaphus (de Escocia), tomada como un grupo de alta variabilidad genética por su origen en una mezcla de diversas subspecies de Cervus elaphus de Europa Occidental; y la población de Cervus nippon en Escocia, como representante de una población completamente empobrecida por constituirse a través de un evento fundador.

Los marcadores microsatélites empleados fueron: (1) diseñados para bóvidos, RM012, BM757, INRA131, IDVGA055, FCB193, TGLA337, HUJ175, BOVIRBP, TGLA127 y FSHB (Slate et al. 1998), (2) diseñados para el ciervo coli-blanco (Odocoileus), Cervid 1 y Cervid 3 (Dewoody et al. 1995) y (3) diseñados para reno, Rangifer tarandus, NVHRT 16, NVHRT 30, NVHRT 71 y NVHRT 73 (Roed \& Midthjell 1998). Esto significa que para el estudio de la estructura y la diversidad genética de poblaciones y especies de cérvidos, al igual que para otros grupos, existe un éxito significativo en el uso de cebadores ("primers") heterólogos para la PCR en la amplificación de loci microsatélites, eliminando esto, la estricta necesidad de desarrollar nuevos conjuntos de cebadores para cada especie determinada.

En el Anexo I se muestran los alelos encontrados, previamente, en $C$. elaphus y $C$. nippon para los marcadores microsatélites de bóvidos, al igual que el rango de tamaños alélicos presentados por los mismos y las temperaturas de anillamiento ("anealling") para cada marcador. Para obtener los correspondientes genotipos se procedió del siguiente modo. Una vez que el ADN fue obtenido a partir de dos procedimientos diferentes (Fenol-Cloroformo y resina Chelex), se llevaron a cabo reacciones de PCR en un volumen de $25 \mu$, cuando el ADN fue extraído de tejido o sangre, con 
CUADRO 1

Muestras de cérvidos neotropicales utilizadas para el análisis de microsatélites de ADN

TABLE 1

Neotropical Cervidae samples employed for the DNA microsatellite analysis

\begin{tabular}{|c|c|c|c|c|}
\hline Especie & $\begin{array}{c}\mathrm{N}^{\mathrm{o}} \text { de } \\
\text { Muestras }\end{array}$ & $\begin{array}{l}\text { Tipo de } \\
\text { Muestra }\end{array}$ & Región & País \\
\hline \multirow[t]{5}{*}{ Odocoileus virginianus } & 9 & Pelo & Cordillera Oriental & Colombia \\
\hline & 7 & Pelo & Cordillera Central & Colombia \\
\hline & 2 & Sangre & WSPA & Colombia \\
\hline & 4 & Pelo & Serranía de Mérida & Venezuela \\
\hline & 1 & Pelo & Peten & Guatemala \\
\hline \multirow[t]{7}{*}{ Mazama americana } & 7 & Pelo & Santa Cruz & Bolivia \\
\hline & 4 & Pelo & Alto Sinú & Colombia \\
\hline & 1 & Tejido & Huila & Colombia \\
\hline & 2 & Pelo & Leticia & Colombia \\
\hline & 6 & Tejido & Iquitos & Perú \\
\hline & 1 & Tejido & & Guyana Francesa \\
\hline & 1 & Pelo & Asunción & Paraguay \\
\hline \multirow[t]{4}{*}{ Mazama gouazoubira } & 2 & Pelo & La Paz & Bolivia \\
\hline & 3 & Tejido & & Guyana Francesa \\
\hline & 2 & Pelo & Serranía de Mérida & Venezuela \\
\hline & 1 & Pelo & Asunción & Paraguay \\
\hline \multirow[t]{2}{*}{ Mazama rufina } & 1 & Tejido & Chocó & Ecuador \\
\hline & 1 & Pelo & Cordillera Oriental & Colombia \\
\hline \multirow[t]{2}{*}{ Pudu mephistopheles } & 1 & Tejido & Andes & Perú \\
\hline & 1 & Pelo & Cordillera Oriental & Colombia \\
\hline Ozotoceros bezoarticus & 2 & Pelo & Santa Cruz & Bolivia \\
\hline \multirow[t]{3}{*}{ Blastocerus dichotomus } & 2 & Pelo & Santa Cruz & Bolivia \\
\hline & 4 & Pelo & $\mathrm{La} \mathrm{Paz}$ & Bolivia \\
\hline & 2 & Pelo & Asunción & Paraguay \\
\hline Hippocamelus antisensis & 4 & Tejido & Salta & Argentina \\
\hline
\end{tabular}

$2.5 \mu 1$ de $\mathrm{MgCl} 22.5 \mu \mathrm{M}, 2.5 \mu \mathrm{l}$ de Buffer 10x, $1 \mu \mathrm{l}$ dNTPs $1 \mathrm{mM}, 1 \mu \mathrm{l}$ de ambos cebadores ("forward" y "reverse") (4 pmol), $14 \mu \mathrm{l}$ de $\mathrm{H}_{2} \mathrm{O}, 0.25$ unidades de Taq polimerasa $(1 \mathrm{u} / \mu \mathrm{l})$ y $2 \mu \mathrm{l}$ de ADN. Cuando el ADN fue extraído de raíz de pelo, el volumen de la reacción de PCR fue de $50 \mu \mathrm{l}$. En este caso se agregaron $20 \mu \mathrm{l}$ de ADN y el doble de las cantidades de reactivos anotadas en el caso anterior. La reacción se llevó a cabo en un termociclador Geneamp PCR System 9600 de Perkin Elmer. Las temperaturas utilizadas para los marcadores de bóvidos fueron 2 min a $94^{\circ} \mathrm{C}$, seguidas de 7 ciclos de $30 \mathrm{~s} \mathrm{a} 94^{\circ} \mathrm{C}, 1 \mathrm{~min}$ a $50^{\circ} \mathrm{C}$ y $30 \mathrm{~s} \mathrm{a} 72^{\circ} \mathrm{C}$ y de 30 ciclos a $94{ }^{\circ} \mathrm{C}, 1 \mathrm{~min} 50^{\circ} \mathrm{C}$ y $30 \mathrm{~s}$ a $72^{\circ} \mathrm{C}$ de extensión. Para los de ciervo coli-blanco fueron 2 min a $94^{\circ} \mathrm{C}$, seguidas de 35 ciclos de $30 \mathrm{~s}$ a $92^{\circ} \mathrm{C}, 1 \mathrm{~min}$ a $60^{\circ} \mathrm{C}$ y $2 \mathrm{~min}$ a $74^{\circ} \mathrm{C}$ y $10 \mathrm{~min}$ a $74^{\circ} \mathrm{C}$ de extensión. Para los marcadores de reno, las temperaturas fueron: $5 \mathrm{~min}$ a $94 \mathrm{oC}$, seguidas de 30 ciclos de 1 min a $95^{\circ} \mathrm{C}, 30 \mathrm{~s}$ a $55^{\circ} \mathrm{C}$ y $1 \mathrm{~min}$ a $72^{\circ} \mathrm{C}$, y $10 \mathrm{~min}$ a $72^{\circ} \mathrm{C}$ de extensión. Los productos de amplificación se almacenaron a $4^{\circ} \mathrm{C}$, hasta el momento en que fueron utilizados. Se procedió a determinar si las muestras utilizadas realmente habían amplificado en un gel de agarosa al 3\% teñido con bromuro de etídio en una cámara de electroforesis horizontal GNA200 de Pharmacia Biotech. Una vez se comprobó qué muestras habían amplificado, se 
corrieron éstas en geles denaturantes de poliacrilamida al $6 \%$ en una cámara vertical Hoefer SQ3 sequencer, con una fuente de poder EPS 3500 de Pharmacia biotech, a $35 \mathrm{~W}$ constantes durante 2-3 horas dependiendo del tamaño del marcador. Posteriormente se paso a la fijación (acido acético), tinción (nitrato de plata, $\mathrm{AgNO}_{3}$ ) y revelado del gel con carbonato de sodio $\left(\mathrm{Na}_{2} \mathrm{CO}_{3}\right)$. El marcador de peso molecular utilizado fue $\phi 174$ cortado con Hind III situado cada 10 carriles.

\section{Métodos genético poblacionales aplica-} dos: Una vez los geles fueron analizados, y se distinguieron perfectamente los genotipos de los especimenes estudiados, se procedió a determinar algunos estadísticos genéticopoblacionales básicos, tales como el número de alelos por marcador, las frecuencias alélicas y la heterocigosis esperada insesgada con el método de Nei (1978). Una pérdida significativa de esta heterocigosis puede indicar claramente la acción de diferentes procesos estocásticos, como la deriva genética, o de procesos selectivos actuando en contra de un alelo particular y, por lo tanto, modificando las frecuencias alélicas (Ruiz-Garcia 1991).

Se procedió al análisis del equilibrio Hardy-Weinberg para algunos de los marcadores moleculares empleados para ciertos conjuntos de muestras. Para ello se utilizaron dos procedimientos diferentes. El primero fue la aplicación del estadístico F de Wright (1965), cuya expresión es:

$\mathrm{F}=1-\left(\mathrm{H}_{\mathrm{o}} / \mathrm{H}_{\mathrm{e}}\right)$, dónde $\mathrm{H}_{\mathrm{o}}$ es el número observado de heterocigotos $\mathrm{y}_{\mathrm{e}}$ es el número de heterocigotos esperados en equilibrio HardyWeinberg. La significación estadística del estadístico $\mathrm{F}$ puede medirse con la expresión:

$\chi^{2}=\mathrm{F}^{2} \mathrm{~N}(\mathrm{~m}-1)$, con $\mathrm{m}(\mathrm{m}-1) / 2$ grados de libertad, dónde $\mathrm{N}$ es el número de individuos analizados y $\mathrm{m}$ es el número de alelos encontrados en cada locus (Li \& Horvitz 1953). El segundo procedimiento analítico empleado fue la aplicación de la $\mathrm{f}$ de Robertson \& Hill (1984). Para cada alelo i, la estima insesgada de la desviación de la frecuencia de homocigotos (ii), respecto a los valores esperados en equilibrio Hardy-Weinberg de estas frecuencias, tiene la siguiente expresión:

$\mathrm{T}_{\mathrm{ii}}=\left[2(2 \mathrm{n}-1) \mathrm{n}_{\mathrm{ii}}-\mathrm{n}_{\mathrm{i}}\left(\mathrm{n}_{\mathrm{i}}-1\right)\right] /[4(\mathrm{n}-1)]$, dónde $n$ es el tamaño de la muestra, $n_{i i}$ es el número de homocigotos observados y $n_{i}$ es el número de alelos i en la muestra estudiada. Para cada alelo, la estima de $\mathrm{f}$ es:

$\mathrm{f}_{\mathrm{ii}}=4 \mathrm{nT}_{\mathrm{ii}} /\left[\mathrm{n}_{\mathrm{i}}\left(2 \mathrm{n}-\mathrm{n}_{\mathrm{i}}\right)\right]$. El estadístico total, para el locus en cuestión, será,

$\mathrm{f}_{\mathrm{T}}=2\left(\mathrm{~T}_{\mathrm{ii}} / \mathrm{n}_{\mathrm{i}}\right) /(\mathrm{m}-1)$, donde $\mathrm{m}$ es el número de alelos detectados en un locus determinado. Ambos, $\mathrm{f}_{\mathrm{ii}}$ y $\mathrm{f}_{\mathrm{T}}$, tienen expresiones matemáticas que permiten calcular la esperanza de sus varianzas.

El índice de fijación $\left(\mathrm{F}_{\mathrm{ST}}\right)$, mide los efectos de la subdivisión de una población, que se traduce en la reducción de la heterocigosis en una subpoblación debido a la deriva genética. Este estadístico se define como: $\mathrm{F}_{\mathrm{ST}}=\left(\mathrm{H}_{\mathrm{T}}-\right.$ $\left.\mathrm{H}_{\mathrm{S}}\right) / \mathrm{H}_{\mathrm{T}}$, dónde $\mathrm{H}_{\mathrm{T}}$ es la heterocigosis esperada en la población total y $\mathrm{H}_{\mathrm{S}}$ es la heterocigosis promedio en el seno de las subpoblaciones. Utilizando $\mathrm{F}_{\mathrm{ST}}$, se calculó el grado de heterogeneidad genética entre diferentes poblaciones de Odocoileus y Mazama, y entre diferentes especies de Mazama. Para ello, se utilizó el procedimiento de Weir \& Cockerham (1984).

Se obtuvieron estimas de flujo génico entre poblaciones de Odocoileus y entre poblaciones de Mazama clasificadas por especies, por regiones biogeográficas respecto a la procedencia de las muestras y por países. Para ello se utilizó el método de los alelos privados (Slatkin 1985) con el programa Genepop versión 3.1 (Raymond \& Rousset 1995).

Empleando el programa Bottleneck versión 1.1.03 (Piry et al. 1999) se calculó la posible existencia de cuellos de botella recientes en las poblaciones de las diferentes especies de ciervos analizadas a partir de la teoría de Cornuet \& Luikart (1996) y Luikart et al. (1998). Esta técnica se basa en el principio por el cual las poblaciones, que han atravesado un cuello 
de botella reciente, pierden simultáneamente número de alelos y niveles de heterocigosis esperada. Sin embargo, el número de alelos $\left(\mathrm{k}_{\mathrm{o}}\right)$ se reduce más rápidamente que los niveles de heterocigosis. De este modo, el valor de la heterocigosis esperada a partir del número de alelos presente $\left(\mathrm{H}_{\mathrm{eq}}\right)$, obtenido por métodos de coalescencia, es menor que la heterocigosis esperada obtenida directamente de las frecuencias alélicas $\left(\mathrm{H}_{\mathrm{e}}\right)$. Este exceso de heterocigosis esperada respecto a la calculada mediante el número de alelos ha sido fehacientemente demostrado en el modelo mutacional de los alelos infinitos, aunque no está tan claradamente determinado para el modelo mutacional "step-wise" (Ohta \& Kimura 1973). Los microsatélites empleados aquí, aunque su dinámica, posiblemente, puede estar más cercana al segundo modelo mutacional, no lo siguen estrictamente y tan pronto como un marcador se aparta ligeramente del modelo "step-wise" hacia el modelo de los alelos infinitos, el exceso de heterocigosis esperada comenzará a incrementarse como consecuencia de un cuello de botella reciente. Para marcadores neutrales, en una población en equilibrio deriva genética-mutación, existe la misma probabilidad que, para un locus dado, haya un ligero exceso o déficit de heterocigosis respecto a este mismo concepto calculado a partir del número de alelos. Por el contrario, una población que ha sufrido un cuello de botella presentará una amplia fracción de loci con un exceso significativo de heterocigosis esperada. Para medir esta probabilidad, se utilizaron cuatro procedimientos: el test del signo, el test de la diferencia estandarizada, el test del signo rango de Wilcoxon, y un descriptor gráfico de la forma de la distribución de las frecuencias alélicas. Una población, que no haya pasado por un cuello de botella, mostrará una distribución en forma L, tal como se espera en una población estable en equilibrio derivamutación. Por el contrario, una población que ha sufrido un cuello de botella reciente mostrará una distribución sesgada. El test de signorango de Wilcoxon es probablemente el más poderoso cuando el número de loci analizados es limitado como ocurre en el presente caso.

\section{RESULTADOS}

Análisis de diversidad genética con loci microsatélites: En la Fig. 1 se pueden observar las frecuencias alélicas de las especies de ciervos neotropicales para los marcadores microsatélites empleados. Puede observarse (Cuadro 2) que la mayor cantidad de alelos fue obtenida para los marcadores Cervid 1, Cervid 3 e IDVGA 55, y que las especies neotropicales con mayor heterocigosis fueron Odocoileus virginianus (heterocigosis insesgada promedio $\mathrm{H}=0.6148)$, Mazama americana $(\mathrm{H}=0.6429)$ y Mazama gouazoubira $(\mathrm{H}=0.7003)$. Los ejemplares del género Cervus no amplificaron para ninguno de los marcadores específicos para Odocoileus y los del género Capreolus no lo hicieron para Cervid 1 ni para RM012. Respecto a los marcadores diseñados para renos, fueron probados únicamente en algunos especimenes y deben considerarse los resultados obtenidos como preliminares. Los ejemplares de Mazama rufina $(\mathrm{H}=0.125)$, Pudu mephistopheles $(\mathrm{H}=0.4062)$, Ozotoceros bezoarticus $(\mathrm{H}=0.50)$, Hippocamelus antisensis $(\mathrm{H}=0.5030)$ y Blastocerus dichotomus $(\mathrm{H}=0.3599)$ presentaron niveles de heterocigosis menores a las especies referidas anteriormente, aunque el número de muestras analizadas fue muy pequeña para algunas de esas especies. Es importante comparar esos niveles de variabilidad genética en los cérvidos neotropicales con los niveles determinados en especies de cérvidos europeos. Para los marcadores diseñados para bóvidos, encontramos que las muestras de los C. elaphus escoceses presentaron elevados niveles de variabilidad genética. Para esos microsatélites, la heterocigosis individual de cada animal analizado osciló entre el 0.7 y 1 . La heterocigosis individual promedio incluyendo todos los C. elaphus escoceses fue de 0.8066 , mientras que la heterocigosis insesgada promedio para el conjunto global de esas muestras fue de 0.8051 . En el otro extremo de la escala, las muestras de C. nippon, introducidos en Gran Bretaña, fueron monomórficas para los 10 microsatélites aplicados en esta especie. Esto es, no se obtuvo 
CUADRO 2

Heterocigosis insesgada esperada, heterocigosis promedio por especie, desviación y número promedio de alelos por locus en ocho especies de ciervos neotropicales y en dos especies de ciervos europeos

TABLE 2

Expected unbiased heterozygosity, average heterozygosity per species, deviation and average allele number per locus for eight Neotropical deer species and in two European deer species

\begin{tabular}{|c|c|c|c|c|c|}
\hline Especie & Locus & $\begin{array}{c}\mathrm{H} \\
\text { insesgada }\end{array}$ & $\mathrm{H}$ promedio & $\begin{array}{l}\text { Desviación } \\
\text { estándar }\end{array}$ & $\begin{array}{l}\text { Alelos promedio } \\
\text { por locus }\end{array}$ \\
\hline \multirow[t]{9}{*}{ Mazama americana } & $\mathrm{Cv} 1$ & 0.886 & 0.6429 & 0.2916 & 5.4444 \\
\hline & $\mathrm{Cv} 3$ & 0.846 & & & \\
\hline & FCB 193 & 0.500 & & & \\
\hline & TGLA 337 & 0.500 & & & \\
\hline & BOVIRBP & 0.375 & & & \\
\hline & IDVGA 55 & 0.812 & & & \\
\hline & NVHRT 16 & 1.000 & & & \\
\hline & NVHRT 73 & 0.200 & & & \\
\hline & NVHRT 71 & 1.000 & & & \\
\hline \multirow[t]{7}{*}{ Mazama gouazoubira } & $\mathrm{Cv} 1$ & 0.820 & 0.7003 & 0.1835 & 5.1429 \\
\hline & $\mathrm{Cv} 3$ & 0.833 & & & \\
\hline & BOVIRBP & 0.625 & & & \\
\hline & IDVGA 55 & 0.812 & & & \\
\hline & NVHRT 16 & 1.000 & & & \\
\hline & NVHRT 71 & 0.500 & & & \\
\hline & NVHRT 30 & 1.000 & & & \\
\hline \multirow[t]{4}{*}{ Mazama rufina } & $\mathrm{Cv} 1$ & 0.500 & 0.1250 & 0.4748 & 1.5000 \\
\hline & $\mathrm{Cv} 3$ & 0.000 & & & \\
\hline & NVHRT 16 & 0.000 & & & \\
\hline & NVHRT 73 & 1.000 & & & \\
\hline \multirow[t]{4}{*}{ Pudu mephistopheles } & Cv 1 & 0.500 & 0.4062 & 0.2772 & 2.0000 \\
\hline & $\mathrm{Cv} 3$ & 0.625 & & & \\
\hline & NVHRT 73 & 0.500 & & & \\
\hline & NVHRT 71 & 0.000 & & & \\
\hline \multirow[t]{9}{*}{ Odocoileus virginianus } & $\mathrm{Cv} 1$ & 0.711 & 0.6148 & 0.1620 & 4.5556 \\
\hline & $\mathrm{Cv} 3$ & 0.857 & & & \\
\hline & FCB 193 & 0.500 & & & \\
\hline & BOVIRBP & 0.320 & & & \\
\hline & IDVGA 55 & 0.784 & & & \\
\hline & NVHRT 16 & 0.611 & & & \\
\hline & NVHRT 73 & 0.625 & & & \\
\hline & NVHRT 71 & 0.500 & & & \\
\hline & NVHRT 30 & 0.625 & & & \\
\hline \multirow[t]{4}{*}{ Ozotoceros bezoarticus } & Cv 1 & 0.625 & 0.5000 & 0.3385 & 2.7500 \\
\hline & $\mathrm{Cv} 3$ & 0.750 & & & \\
\hline & BOVIRBP & 0.000 & & & \\
\hline & IDVGA 55 & 0.625 & & & \\
\hline
\end{tabular}


CUADRO 2 (Contnuación)

Heterocigosis insesgada esperada, heterocigosis promedio por especie, desviación y número promedio de alelos por locus en ocho especies de ciervos neotropicales y en dos especies de ciervos europeos

TABLE 2 (Continued)

Expected unbiased heterozygosity, average heterozygosity per species, deviation and average allele number per locus for eight Neotropical deer species and in two European deer species

\begin{tabular}{|c|c|c|c|c|c|}
\hline Especie & Locus & $\begin{array}{c}\mathrm{H} \\
\text { insesgada }\end{array}$ & $\mathrm{H}$ promedio & $\begin{array}{l}\text { Desviación } \\
\text { estándar }\end{array}$ & $\begin{array}{l}\text { Alelos promedio } \\
\text { por locus }\end{array}$ \\
\hline \multirow[t]{7}{*}{ Blastocerus dichotomus } & $\mathrm{Cv} 1$ & 0.458 & 0.3599 & 0.3586 & 2.8571 \\
\hline & Cv 3 & 0.781 & & & \\
\hline & FCB 193 & 0.000 & & & \\
\hline & TGLA 337 & 0.500 & & & \\
\hline & BOVIRBP & 0.000 & & & \\
\hline & IDVGA 55 & 0.780 & & & \\
\hline & NVHRT 16 & 0.000 & & & \\
\hline \multirow[t]{2}{*}{ Hippocamelus antisensis } & Cv 1 & 0.444 & 0.5030 & 0.0834 & 3.0000 \\
\hline & $\mathrm{Cv} 3$ & 0.562 & & & \\
\hline \multirow[t]{4}{*}{ Capreolus capreolus } & $\mathrm{Cv} 3$ & 0.804 & 0.3173 & 0.3916 & 3.5000 \\
\hline & BOVIRBP & 0.465 & & & \\
\hline & NVHRT 16 & 0.000 & & & \\
\hline & NVHRT 73 & 0.000 & & & \\
\hline Capreolus pygargus & BOVIRBP & 0.594 & 0.5940 & ----- & 3.0000 \\
\hline
\end{tabular}

diversidad genética alguna $(\mathrm{H}=0)$. El nivel estimado de diversidad genética en las muestras de C. elaphus procedentes de Italia fue considerablemente menor que el nivel encontrado para la población británica. Los animales, individualmente, poseyeron niveles de heterocigosis entre 0.166 y 0.6 . El valor de la heterocigosis individual promedio fue de 0.383 , mientras que la heterocigosis insesgada global para toda la muestra fue de 0.556. Los tamaños alélicos encontrados en los C. elaphus italianos coinciden con los tamaños alélicos encontrados en los británicos, aún cuando pueden pertenecer a subespecies diferentes. Capreolus capreolus presentó alelos similares en tamaño $(95,100$ pares de bases, pb) a los reportados para Cervus en el marcador INRA131. Contrariamente, los alelos encontrados para esta especie, en TGLA337, son mucho más pequeños $(112,114$ $\mathrm{pb}$ ) que los reportados para Cervus (128 pb en adelante). Los C. capreolus de origen italiano, para este ultimo marcador, estuvieron fijados para un alelo de $112 \mathrm{pb}$, mientras que los de origen español lo estuvieron para un alelo de 114 pb. Capreolus mostró un alelo de 143 pb, para HUJ175, de tamaño mayor que los reportados para Cervus elaphus (115-133 pb). La heterocigosis individual promedio fue de 0.333 para C. capreolus. El marcador que presentó mayor variabilidad en las muestras de Dama dama procedentes de España fue TGLA337, con tres alelos de 124, 134 y $138 \mathrm{pb}(\mathrm{H}=0.333)$. El tamaño de esos alelos está dentro del rango de los encontrados en C. elaphus. En cambio, los del bóvido Rupicapra pyrenaica resultaron ostensiblemente menores (104, 108, 112, 118 pb) para ese marcador. D. dama italiano mostró un alelo de 123 pb para el marcador FCB193, lo cual coincide con el tamaño de los alelos reportados, anteriormente, para C. elaphus (97$121 \mathrm{pb}$ ) y para $C$. nippon (123-139 pb).

Los cérvidos neotropicales analizados presentaron una variabilidad genética intermedia respecto a los dos extremos representados por C. elaphus y C.nippon. Mientras que Mazama americana, M. gouzaoubira y Odocoileus 


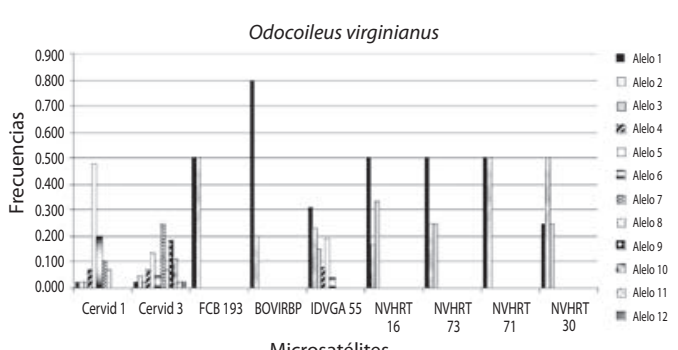

Microsatélites
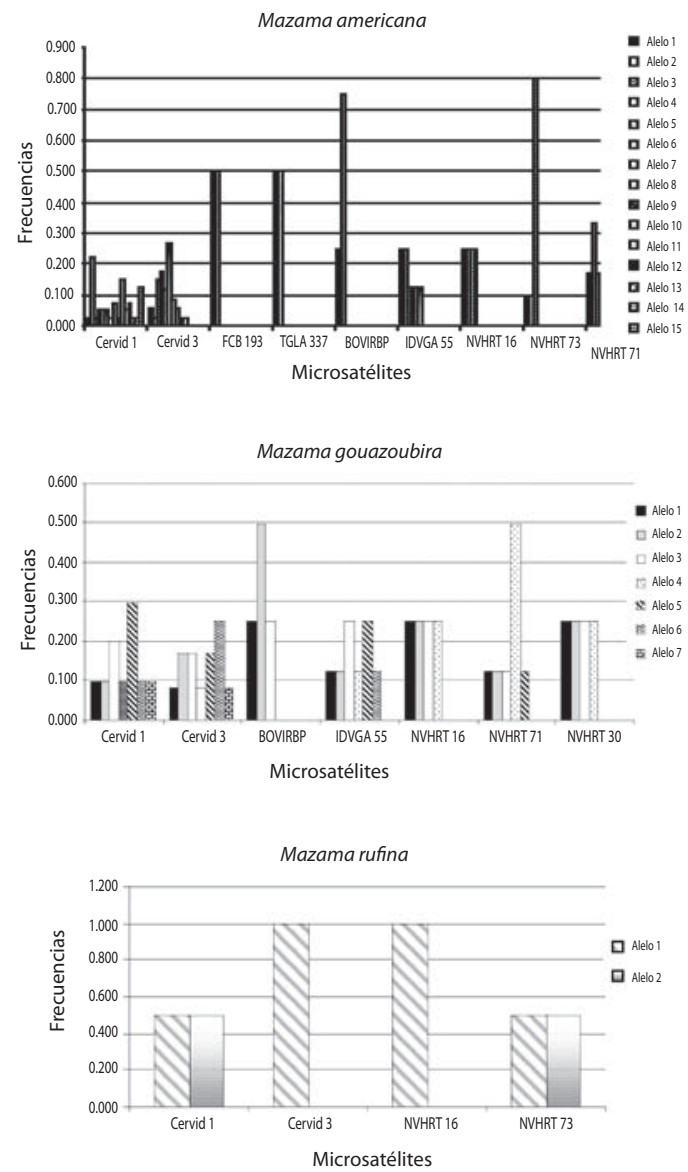
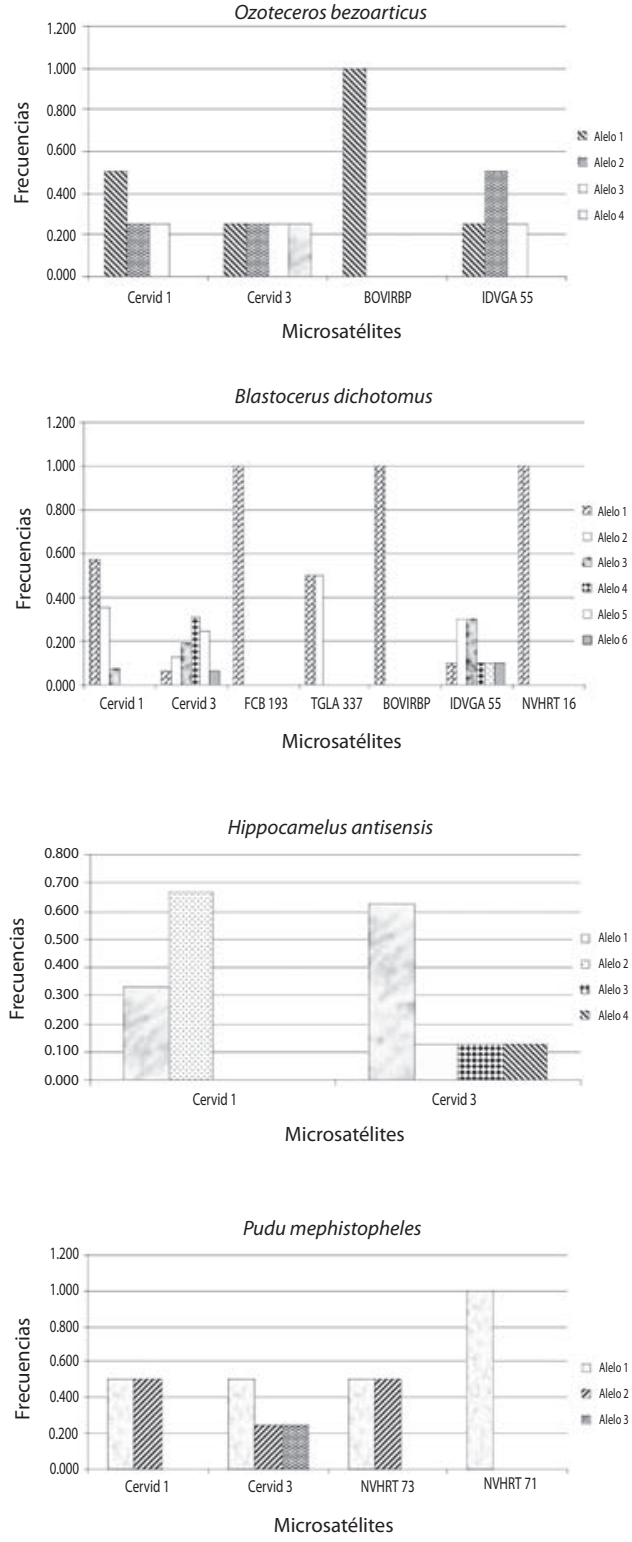

Fig. 1. Frecuencias alélicas de los marcadores microsatélites que presentaron más variabilidad genética en ocho especies de cérvidos neotropicales.

Fig. 1. Allele frequencies of the microsatellite markers which presented more genetic variability in eight neotropical deer species. 
virginianus presentaron valores de heterocigosis bastante elevados, cercanos al conspicuo valor de $\operatorname{los} C$. elaphus escoceses $(\mathrm{H}=0.71$ en el estudio de Goodman et al. 2001; $\mathrm{H}=0.8066$ en el presente estudio), las otras especies de ciervos neotropicales estudiados presentan niveles de variabilidad genética menores, pero nunca con un valor tan extremo en su pobreza como el estimado, y aquí mostrado, en C. nippon.

En el Cuadro 3 se presentan los grupos de muestras de cérvidos neotropicales que mostraron no estar en equilibrio Hardy-Weinberg. En general estas asociaciones se caracterizaron por ser poblaciones "artificiales". Esto hace referencia al hecho de asociar muestras procedentes de diferentes regiones geográficas e, inclusive, de diferentes especies dentro del mismo género (caso de Mazama), lo que pone en evidencia, la existencia de efecto Wahlund (=subdivision) por la existencia de acervos genéticos diferenciados en el seno de los géneros Mazama y Odocoileus en Latinoamérica. Este hecho viene dado por la gran cantidad de dudas taxonómicas que se han reportado para Mazama intragenéricamente $\mathrm{y}$, por ello, se trabajó este género como una población total con diferentes subpoblaciones: una única población global (tomando todas las muestras de Mazama como una única población), por países, sin importar las especies, y por especies (o subespecies) teniendo en consideración las regiones biogeográficas de procedencia de las muestras. Como hasta el momento actual se desconoce cuantos y cuáles pueden ser los acervos genéticos diferentes en el seno de Odocoileus virginianus en Latinoamérica y en el seno de cada especie de Mazama e, incluso, cuantas especies diferentes de Mazama pueden existir, una forma de detectar la posible existencia de diferentes acervos genéticos es mediante la detección de efecto Wahlund, el cual se caracteriza por mostrar un exceso significativo de homocigotos. Por ejemplo, el grupo total de Mazama mostró un déficit significativo de heterocigotos para los marcadores Cervid $1(\mathrm{p}=0.0041)$, Cervid 3 $(\mathrm{p}=0.0000)$, IDVGA $55(\mathrm{p}=0.0105)$ y NVHRT $71(\mathrm{p}=0.0104)$ y para el conjunto global de todos los marcadores analizados en este género tomado como un todo $(\mathrm{p}=0.0000)$. Esto significa que no existe un único acervo genético para el género Mazama en toda la extensión geográfica analizada en Latinoamérica. Los individuos de Mazama agrupados por países también mostraron un fuerte exceso de homocigotos para el marcador Cervid $1(\mathrm{p}=0.0022)$ y Cervid 3 ( $p=0.0073$ ) en el caso de Colombia (lo cual denota la existencia de diferentes acervos genéticos para esos marcadores en la población de Mazama en ese país sudamericano), o para Cervid 3 ( $\mathrm{p}=0.0422$ ) en el caso de las Mazama de Bolivia. También, el taxón Mazama americana proveniente de la región amazónica peruana de Loreto mostró no estar en equilibrio Hardy-Weinberg para Cervid 3 ( $\mathrm{p}=0.0157)$, ni para el conjunto global de todos los marcadores analizados $(\mathrm{p}=0.0000)$. Cuando se analizó el grupo total de Mazama americana, independientemente de los países de procedencia de las muestras, se encontró un defecto significativo de heterocigotos para Cervid $3(\mathrm{p}=0.0017)$, para IDVGA55 $(\mathrm{p}=0.0218)$ y para el conjunto global de marcadores $(\mathrm{p}=0.0021)$. Igualmente, al analizar el conjunto global de Mazama gouzaoubira se encontró un déficit de heterocigotos para Cervid $1(\mathrm{p}=0.0421)$, Cervid $3(\mathrm{p}=0.0014)$ y para el conjunto global de todos los marcadores analizados $(\mathrm{p}=0.0052)$. Este descubrimiento revela la existencia de diferentes acervos genéticos en el seno de Mazama americana y de Mazama gouzaoubira, respectivamente. Por el contrario, no se encontraron desviaciones respecto al equilibrio Hardy-Weinberg para los conjuntos de muestras de Mazama gouzaoubira de Venezuela, Guyana Francesa, y Bolivia, ni para las agrupaciones de muestras de M. americana del departamento de Córdoba (Alto Sinú, Colombia), Bolivia y M. rufina, lo que puede significar que las muestras obtenidas en esas regiones geográficas forman acervos genéticos únicos bien definidos. Tampoco se registró ningún caso de desviación respecto al equilibrio Hardy-Weinberg para los conjuntos muestrales de Blastoceros dichotomus, Ozotoceros bezoarticus, Pudu mephistopholes, o Hippocamelus antisensis. Contrariamente, en el caso del género Odocoileus se registraron algunos casos 
CUADRO 3

Especies y géneros de cérvidos neotropicales y europeos que no presentaron equilibrio Hardy-Weinberg

TABLE 3

Species and genera of Neotropical and European deers, which were not in Hardy-Weinberg equilibrium

\begin{tabular}{|c|c|c|c|}
\hline Especies & Región & Loci & $\mathrm{p}$ \\
\hline \multirow[t]{12}{*}{ Mazama sp. } & \multirow[t]{5}{*}{ Todas las especies del género } & Cv1 & 0.0041 \\
\hline & & Cv3 & 0.0000 \\
\hline & & IDVGA55 & 0.0105 \\
\hline & & NVHRT71 & 0.0104 \\
\hline & & Todos los loci & 0.0000 \\
\hline & Bolivia & Cv3 & 0.0422 \\
\hline & \multirow[t]{3}{*}{ Colombia } & Cv1 & 0.0022 \\
\hline & & Cv3 & 0.0073 \\
\hline & & Todos los loci & 0.0002 \\
\hline & \multirow[t]{2}{*}{ Perú } & Cv3 & 0.0259 \\
\hline & & Todos los loci & 0.0000 \\
\hline & Todos los países & Todos los loci & 0.0011 \\
\hline \multirow[t]{5}{*}{ Mazama americana } & \multirow[t]{3}{*}{ Todas las regiones } & Cv3 & 0.0017 \\
\hline & & IDVGA55 & 0.0218 \\
\hline & & Todos los loci & 0.0021 \\
\hline & \multirow[t]{2}{*}{ Perú } & Cv3 & 0.0157 \\
\hline & & Todos los loci & 0.0000 \\
\hline \multirow[t]{3}{*}{ Mazama gouazoubira } & \multirow[t]{3}{*}{ Todas las regiones } & Cv1 & 0.0421 \\
\hline & & Cv3 & 0.0014 \\
\hline & & Todos los loci & 0.0052 \\
\hline \multirow[t]{8}{*}{ Odocoileus virginianus } & \multirow[t]{3}{*}{ Todas las regiones } & Cv1 & 0.0225 \\
\hline & & Cv3 & 0.0022 \\
\hline & & Todos los loci & 0.0007 \\
\hline & \multirow[t]{2}{*}{ Guatemala y Venezuela } & Cv1 & 0.0000 \\
\hline & & FCB 193 & 0.0000 \\
\hline & \multirow[t]{3}{*}{ Colombia } & Cv1 & 0.0002 \\
\hline & & Cv3 & 0.0465 \\
\hline & & Todos los loci & 0.0001 \\
\hline \multirow[t]{2}{*}{ Capreolus capreolus } & \multirow[t]{2}{*}{ Italia } & Cv3 & 0.0427 \\
\hline & & Todos los loci & 0.0085 \\
\hline
\end{tabular}

- Únicamente se muestran aquellos marcadores que no mostraron el citado equilibrio. p=probabilidad.

- Only those markers which were not in Hardy-Weinberg equilibrium are herein shown. $\mathrm{p}=$ probability. 
de desviación respecto al equilibrio HardyWeinberg por exceso de homocigotos. Para el conjunto global de todas las muestras estudiadas de $O$. virginianus se detectó este fenómeno para los marcadores Cervid $1 \quad(\mathrm{p}=0.0225)$, Cervid $3(\mathrm{p}=0.0022)$ y para el conjunto global de marcadores analizados $(p=0.0007)$, al igual que para el grupo total de ejemplares procedentes de Colombia ( $\mathrm{p}=0.0002 ; \mathrm{p}=0.0465$ y $\mathrm{p}=0.0001$, respectivamente). Por lo tanto, en Odocoileus virginianus a nivel global de
Latinoamérica y a nivel de Colombia, al igual que en el caso global de Mazama, encontramos evidencia de la existencia de acervos genéticos altamente diferenciados. En el Cuadro 4, se muestran los resultados, para los marcadores analizados más polimórficos, de los estadisticos f de Robertson \& Hill (1984) y F de Wright (1965) para las poblaciones de cérvidos europeos. Contrariamente a lo encontrado para las poblaciones de ciervos latinoamericanos, todas las muestras de ciervos europeos mostraron

\section{CUADRO 4}

Análisis del equilibrio Hardy-Weinberg, para loci microsatélites, aplicados a algunas especies de cérvidos europeos y al bóvido, Rupricapra pyrenaica

TABLE 4

Hardy-Weinberg equilibrium analysis for microsatellite loci applied to several European Cervidae species and to the Bovidae, Rupricapra pyrenaica

\begin{tabular}{|c|c|c|c|c|c|c|c|}
\hline & $\mathrm{f}$ & $\chi^{2}$ & $\mathrm{p}$ & $\mathrm{F}$ & g. de 1 . & $\chi^{2}$ & $\mathrm{H}$ \\
\hline \multicolumn{8}{|l|}{ RM012 } \\
\hline Cervus elaphus (ESCOCIA) & -0.1563 & 0.488 & 0.4847 & -0.282 & 10 & 1.591 & 0.867 \\
\hline Cervus elaphus (ITALIA) & -1.0000 & 2.000 & 0.1573 & -1.000 & 1 & 2.000 & 0.667 \\
\hline \multicolumn{8}{|l|}{ BM757 } \\
\hline Cervus elaphus (ESCOCIA) & -0.0625 & 0.059 & 0.8087 & -0.212 & 6 & 1.563 & 0.733 \\
\hline \multicolumn{8}{|l|}{ FCB 193} \\
\hline Cervus elaphus (ESCOCIA) & -0.1000 & 0.250 & 0.6171 & -0.250 & 15 & 1.563 & 0.889 \\
\hline \multicolumn{8}{|l|}{ HUJI 175} \\
\hline Cervus elaphus (ESCOCIA) & 0.1719 & 0.591 & 0.4420 & 0.167 & 10 & 0.556 & 0.800 \\
\hline \multicolumn{8}{|l|}{ TGLA 127} \\
\hline Cervus elaphus (ESCOCIA) & 0.1719 & 0.937 & 0.3330 & -0.389 & 6 & 2.269 & 0.800 \\
\hline \multicolumn{8}{|l|}{ INRA 131} \\
\hline Cervus elaphus (ESCOCIA) & -0.2500 & 0.937 & 0.3329 & -0.428 & 6 & 2.755 & 0.778 \\
\hline \multicolumn{8}{|l|}{ IDVGA 55} \\
\hline Cervus elaphus (ESCOCIA) & -0.1000 & 0.150 & 0.6985 & -0.212 & 6 & 0.675 & 0.773 \\
\hline \multicolumn{8}{|l|}{ TGLA 337} \\
\hline Cervus elaphus (ESCOCIA) & 0.0125 & 0.002 & 0.9685 & 0.032 & 3 & 0.010 & 0.689 \\
\hline Cervus elaphus (ITALIA) & 0.0000 & 0.000 & 1.0000 & -0.333 & 1 & 0.222 & 0.500 \\
\hline Dama dama (ESPAÑA) & 0.6667 & 2.667 & 0.1025 & 0.454 & 3 & 1.240 & 0.733 \\
\hline Rupicapra pyrenaica (ESPAÑA) & -0.2222 & 0.593 & 0.4444 & -0.391 & 6 & 1.837 & 0.821 \\
\hline \multicolumn{8}{|l|}{ BOVIRBP } \\
\hline Cervus elaphus (ESCOCIA) & 0.5000 & 1.000 & 0.3170 & 0.200 & 3 & 0.160 & 0.833 \\
\hline \multicolumn{8}{|l|}{ FSHB } \\
\hline Cervus elaphus (ESCOCIA) & 0.4000 & 3.200 & 0.0736 & 0.384 & 15 & 2.959 & 0.929 \\
\hline
\end{tabular}

- f=estadístico de Robertson \& Hill (1984). F =estadístico de Wright (1965). p= Probabilidad. g. de 1. =grados de libertad. $\mathrm{H}=$ heterocigosis insesgada de Nei (1978).

- $\mathrm{f}=$ Robertson \& Hill's f statistic (1984). F =Wright's F statistic (1965). p=Probability. g de l=degrees of freedom. H=Nei's (1978) unbiased heterozygosity. 
estar en equilibrio Hardy-Weinberg, con la excepción de Capreolus capreolus en Italia.

Heterogeneidad genética entre cérvidos neotropicales: El Cuadro 5 muestra los valores de la heterogeneidad genética, medida mediante el estadístico $\mathrm{F}_{\mathrm{ST}} \mathrm{y}$ sus probabilidades exactas asociadas, entre diversas poblaciones de Mazama conformadas a partir de los países de procedencia de las muestras, mientras que los Cuadros 6, 7 y 8 muestran las heterogeneidades medidas de idéntica forma para las diversas poblaciones analizadas de Mazama americana, para las diferentes poblaciones estudiadas de Odocoileus virginianus y para los diferentes pares analizados de especies del género Mazama. También se muestra en el Cuadro 9, las estimas teóricas de flujo génico entre diferentes agrupaciones geográficas de Mazama y de Odocoileus virginianus. Como se observa, existe heterogeneidad genética significativa entre diversas poblaciones de Mazama y de Odocoileus, respectivamente, en la mayor parte de los casos. Algunos ejemplos notables son los siguientes. Las poblaciones totales de Mazama de Colombia y Perú difirieron significativamente para el marcador Cervid 1 ( $\mathrm{p}=0.04192)$, al igual que la población de Perú difirió significativamente de la de Venezuela $(\mathrm{p}=0.01386)$. El conjunto global de todas las poblaciones de Mazama por países (Bolivia, Guyana, Colombia, Perú, Ecuador y Paraguay) para ese mismo marcador, también, mostró heterogeneidad significativa $(p=0.01938)$. El marcador Cervid 3 mostró diferencias entre la población total de Mazama de Bolivia y Venezuela $(\mathrm{p}=0.0058)$, de Colombia y Perú $(\mathrm{p}=0.0344)$, de Colombia y Venezuela $(\mathrm{p}=0.02036)$ y de Perú y Venezuela $(\mathrm{p}=0.04104)$. También fue significativa la heterogeneidad genética para todo el conjunto de poblaciones de Mazama para Cervid $3(\mathrm{p}=0.0041)$. Cuando se comparó entre especies de Mazama, las diferencias fueron significativas para el marcador Cervid 1 entre $M$. americana y $M$. rufina $(\mathrm{p}=0.0316)$ y para la comparación englobando las tres especies de este género $(\mathrm{p}=0.02249)$.

CUADRO 5

Diferenciación génica entre pares de poblaciones de Mazama sp.

TABLE 5

Genic differentiation among population pairs of Mazama sp.

\begin{tabular}{|c|c|c|c|c|c|c|c|}
\hline Cervid 1/Cervid 3 & Bolivia & Guyana & Paraguay & Colombia & Perú & Ecuador & Venezuela \\
\hline Bolivia & --- & 0.5621 & 0.7847 & 0.2866 & 0.0653 & 0.5118 & 0.8986 \\
\hline Guyana & 0.3071 & --- & 0.4638 & 0.1471 & 0.1505 & 0.3348 & 0.2002 \\
\hline Paraguay & 0.1725 & 0.4783 & --- & 0.1838 & 0.0745 & 0.2018 & 0.0853 \\
\hline Colombia & 0.0505 & 0.6910 & 0.0884 & --- & $* 0.0419$ & 0.3666 & 0.1628 \\
\hline Perú & 0.3912 & 0.0986 & 0.4182 & $* 0.0344$ & --- & 0.0680 & $* 0.0138$ \\
\hline Ecuador & $\mathrm{N}$ & $\mathrm{N}$ & $\mathrm{N}$ & $\mathrm{N}$ & $\mathrm{N}$ & --- & 0.2069 \\
\hline Venezuela & $* 0.0058$ & 0.2088 & 0.1413 & $* 0.0203$ & $* 0.0410$ & $\mathrm{~N}$ & --- \\
\hline \multicolumn{8}{|c|}{ Análisis global del marcador: } \\
\hline Cervid 1 & $* 0.0193$ & & & & & & \\
\hline Cervid 3 & $* 0.0041$ & & & & & & \\
\hline IDVGA 55/BOVIRBP & Bolivia & Paraguay & Venezuela & & & & \\
\hline Bolivia & --- & 0.2946 & 0.4625 & & & & \\
\hline Paraguay & 1.0000 & --- & 0.2032 & & & & \\
\hline Venezuela & 1.0000 & $\mathrm{~N}$ & --- & & & & \\
\hline \multicolumn{8}{|c|}{ Análisis global del marcador: } \\
\hline IDVGA 55 & 1.0000 & & & & & & \\
\hline BOVIRBP & 0.0925 & & & & & & \\
\hline
\end{tabular}


CUADRO 5 (Continuación)

Diferenciación génica entre pares de poblaciones de Mazama sp.

TABLE 5 (Continued)

Genic differentiation among population pairs of Mazama $s p$.

\begin{tabular}{|c|c|c|c|c|c|c|c|}
\hline Cervid $1 /$ Cervid 3 & Bolivia & Guyana & Paraguay & Colombia & Perú & Ecuador & Venezuela \\
\hline NVHRT 73/NVHRT 16 & Bolivia & Paraguay & Ecuador & Venezuela & Perú & & \\
\hline Bolivia & --- & 1.0000 & 0.3327 & 1.0000 & $\mathrm{~N}$ & & \\
\hline Paraguay & $\mathrm{N}$ & --- & 0.3308 & 1.0000 & $\mathrm{~N}$ & & \\
\hline Ecuador & 1.0000 & $\mathrm{~N}$ & --- & 0.3301 & $\mathrm{~N}$ & & \\
\hline Venezuela & $\mathrm{N}$ & $\mathrm{N}$ & $\mathrm{N}$ & --- & $\mathrm{N}$ & & \\
\hline Perú & 1.0000 & $\mathrm{~N}$ & 0.3722 & $\mathrm{~N}$ & --- & & \\
\hline \multicolumn{8}{|c|}{ Análisis global del marcador: } \\
\hline NVHRT 73 & 0.2468 & & & & & & \\
\hline NVHRT 16 & 0.5726 & & & & & & \\
\hline NVHRT 71 & Guyana & Perú & Venezuela & & & & \\
\hline Guyana & --- & 0.8989 & 1.0000 & & & & \\
\hline Perú & & --- & 0.4708 & & & & \\
\hline Venezuela & & & --- & & & & \\
\hline \multicolumn{8}{|c|}{ Análisis global del marcador: } \\
\hline NVHRT 71 & 0.8890 & & & & & & \\
\hline TODOS LOS MARCAD & RES & $* 0.0142$ & & & & & \\
\hline
\end{tabular}

- Los valores de las matrices corresponden a los valores de la probabilidad (p) obtenidos a partir del estadístico $\mathrm{F}_{\mathrm{st}}$. Por encima y por debajo de la diagonal principal se muestran los valores de p para pares de microsatélites diferentes. *Diferencia significativa $(\mathrm{p}=0.05)$. $\mathrm{N}=$ no se obtuvo el correspondiente valor por tamaño muestral muy pequeño.

- The matrix values belong to the probability $(\mathrm{p})$ obtained throughtout the $\mathrm{F}_{\mathrm{st}}$ statistic. The values above and below of the main matrix diagonal are $\mathrm{p}$ for two different microsatellites. * Significant differences $(\mathrm{p}=0.05) . \mathrm{N}=$ the value was not calculated since the sample sizes were very low.

\section{CUADRO 6}

Diferenciación génica entre pares de poblaciones de Mazama americana

TABLA 6

Genic differentiation among population pairs of Mazama americana

\begin{tabular}{lcccccccc}
\multicolumn{1}{r}{ Cervid 3/Cervid 1 } & Bolivia & Córdoba & Leticia & Perú & Guyana & Paraguay & Huila \\
Bolivia & --- & 0.2316 & 0.2000 & 0.5639 & $\mathrm{~N}$ & 0.1155 & $\mathrm{~N}$ \\
Córdoba & 0.3269 & --- & 0.2121 & 0.0155 & $\mathrm{~N}$ & 0.2083 & $\mathrm{~N}$ \\
Leticia & 0.6397 & $* 0.0119$ & --- & 0.5997 & $\mathrm{~N}$ & 1.0000 & $\mathrm{~N}$ \\
Perú & 0.0986 & $* 0.0130$ & 0.2126 & --- & $\mathrm{N}$ & 0.3027 & $\mathrm{~N}$ \\
Guyana & 0.2643 & 0.2403 & 0.2034 & 0.1645 & --- & $\mathrm{N}$ & $\mathrm{N}$ \\
Paraguay & 1.0000 & 0.1561 & 0.6063 & 0.3432 & 1.0000 & --- & $\mathrm{N}$ \\
Huila & 0.7564 & 0.153 & 1.0000 & 0.3239 & 1.0000 & 1.0000 & --- \\
Análisis global del marcador: & $* 0.0349$ & & & & & & & \\
Cervid 3 & $* 0.0057$ & & & & & & &
\end{tabular}


CUADRO 6 (Continuación)

Diferenciación génica entre pares de poblaciones de Mazama americana

TABLA 6 (Continued)

Genic differentiation among population pairs of Mazama americana

\begin{tabular}{|c|c|c|c|c|c|c|c|}
\hline Cervid 3/Cervid 1 & Bolivia & Córdoba & Leticia & Perú & Guyana & Paraguay & Huila \\
\hline NVHRT 71/NVHRT 73 & Bolivia & Perú & Guyana & & & & \\
\hline Bolivia & --- & $\mathrm{N}$ & $\mathrm{N}$ & & & & \\
\hline Perú & 1.0000 & --- & 1.0000 & & & & \\
\hline Guyana & $\mathrm{N}$ & $\mathrm{N}$ & --- & & & & \\
\hline BOVIRBP/IDVGA 55 & Bolivia & Paraguay & & & & & \\
\hline Bolivia & --- & 1.0000 & & & & & \\
\hline Paraguay & 0.2851 & --- & & & & & \\
\hline TODOS LOS MARCAD & & 0.0671 & & & & & \\
\hline
\end{tabular}

- Los valores de las matrices corresponden a los valores de la probabilidad ( $\mathrm{p}$ ) obtenidos a partir del estadístico $\mathrm{F}_{\mathrm{st}}$. Por encima y por debajo de la diagonal principal se muestran los valores de p para pares de microsatélites diferentes. *Diferencia significativa $(\mathrm{p}=0.05)$. $\mathrm{N}=$ no se obtuvo el correspondiente valor por tamaño muestral muy pequeño.

- The matrix values belong to the probability (p) obtained throughtout the $\mathrm{F}_{\text {st }}$ statistic. The values above and below of the main matrix diagonal are $\mathrm{p}$ for two different microsatellites. *Significant differences $(\mathrm{p}=0.05) . \mathrm{N}=$ the value was not calculated since the sample sizes were very low.

\section{CUADRO 7}

Diferenciación génica entre pares de poblaciones de Odocoileus virginianus

TABLE 7

Genic differentiation among population pairs of Odocoileus virginianus

\begin{tabular}{|c|c|c|c|c|}
\hline Cervid 3/Cervid 1 & Bolivia & Guyana & Venezuela & Paraguay \\
\hline \multicolumn{5}{|l|}{ A } \\
\hline Bolivia & --- & 0.1996 & $* 0.0250$ & 0.1936 \\
\hline Guyana & $\mathrm{N}$ & --- & 0.2005 & 0.3335 \\
\hline Venezuela & 0.4871 & $\mathrm{~N}$ & --- & 0.0688 \\
\hline Paraguay & 1.0000 & $\mathrm{~N}$ & 0.2026 & --- \\
\hline \multicolumn{5}{|l|}{ Análisis global del marcador: } \\
\hline Cervid 3 & $* 0.0004$ & & & \\
\hline Cervid 1 & 0.2703 & & & \\
\hline IDVGA 55/BOVIRBP & Bolivia & Venezuela & Paraguay & \\
\hline Bolivia & --- & 0.4783 & 0.1983 & \\
\hline Venezuela & 0.3349 & --- & 0.3323 & \\
\hline Paraguay & $\mathrm{N}$ & $\mathrm{N}$ & --- & \\
\hline \multicolumn{5}{|l|}{ Análisis global del marcador: } \\
\hline IDVGA 55 & 0.0865 & & & \\
\hline BOVIRBP & 0.3416 & & & \\
\hline
\end{tabular}


CUADRO 7 (Continuación)

Diferenciación génica entre pares de poblaciones de Odocoileus virginianus

TABLE 7 (Continued)

Genic differentiation among population pairs of Odocoileus virginianus

\begin{tabular}{lcccc}
\multicolumn{1}{r}{ Cervid 3/Cervid 1 } & Bolivia & Guyana & Venezuela & Paraguay \\
NVHRT 71/NVHRT 16 & Venezuela & Paraguay & Guyana \\
Venezuela & --- & $\mathrm{N}$ & 1.0000 \\
Paraguay & 1.0000 & --- & $\mathrm{N}$ \\
Guyana & $\mathrm{N}$ & $\mathrm{N}$ & ---
\end{tabular}

TODOS LOS MARCADORES

$* 0.0005$

$\mathrm{B}$

Cervid 3/Cervid 1

Colombia

Venezuela

Análisis global del marcador:

$\begin{array}{cc}\text { Colombia } & \text { Venezuela } \\ --- & 0.0636\end{array}$

$* 0.0191$

Venezuela

Análisis global del marcador:

TODOS LOS MARCADORES

$$
\text { C }
$$

Cervid 3/Cervid 1

Oriental

Central

Colombia

Venezuela

---

0.0731

0.2993

$* 0.0071$

Análisis global del marcador:

BOVIRBP/IDVGA 55

Oriental

Central

Análisis global del marcador:

TODOS LOS MARCADORES
Oriental

Central

$---$

1.0000

0.2444

$\begin{array}{cc}\text { Oriental Central } \\ --- & 1.0000\end{array}$

0.8571

$\begin{array}{cc}\text { Oriental } & \text { Central } \\ --- & 0.6562 \\ 0.9336 & ---\end{array}$

- Los valores de las matrices corresponden a los valores de la probabilidad (p) obtenidos a partir del estadístico $\mathrm{F}_{\mathrm{st}}$. Por encima y por debajo de la diagonal principal se muestran los valores de p para pares de microsatélites diferentes. *Diferencia significativa $(\mathrm{p}=0.05)$. $\mathrm{N}=$ no se obtuvo el correspondiente valor por tamaño muestral muy pequeño. $=$ Heterogeneidad genética entre muestras de Bolivia, Guyana, Venezuela y Paraguay. B =Heterogeneidad genética entre las muestras obtenidas en Colombia y Venezuela. $\mathrm{C}=$ Heterogeneidad genética entre muestras procedentes de la Cordillera Oriental y Central de Colombia.

- The matrix values belong to the probability (p) obtained throughtout the $\mathrm{F}_{\mathrm{st}}$ statistic. The values above and below of the main matrix diagonal are $\mathrm{p}$ for two different microsatellites. *Significant differences $(\mathrm{p}=0.05)$. $\mathrm{N}=$ the value was not calculated since the sample sizes were very low. $\mathrm{A}=$ Genetic heterogeneity between samples from Bolivia, Guyana, Venezuela and Paraguay. $\mathrm{B}=$ Genetic heterogeneity between samples from Colombia and Venezuela. $\mathrm{C}=$ Genetic heterogeneity between samples from the Eastern and Central Andean cordilleras in Colombia. 
CUADRO 8

Diferenciación génica entre pares de especies de Mazama

TABLE 8

Genic differentiation among species pairs of Mazama

\begin{tabular}{lccc}
\multicolumn{1}{c}{ Cervid 3/Cervid 1 } & M. americana & M. rufina & M. gouazoubira \\
M. americana & -- & $* 0.0112$ & $* 0.0405$ \\
M. rufina & $* 0.0316$ & -- & -0849 \\
M. gouazoubira & 0.1235 & 0.5157 & --- \\
Análisis global del marcador: & $* 0.0038$ & & \\
Cervid 3 & $* 0.0249$ & & M. gouazoubira \\
Cervid 1 & M. americana & 1.0000 & M. gouazoubira \\
BOVIRBP/IDVGA 55 & --- & --- & $\mathrm{N}$ \\
M. americana & 0.1813 & & $\mathrm{~N}$ \\
M. gouazoubira & & M. rufina & --- \\
NVHRT 73/NVHRT 16 & M. americana & 0.3153 & --- \\
M. americana & --- & 0.4619 & \\
M. rufina & 0.3304 & & \\
M. gouazoubira & 1.0000 & M. gouazoubira & \\
NVHRT 71 & M. americana & $* 0.0055$ & --- \\
M. americana & --- & 0.0658 & \\
M. gouazoubira & & & \\
TODOS LOS MARCADORES & & &
\end{tabular}

- Los valores de las matrices corresponden a los valores de la probabilidad (p) obtenidos a partir del estadístico $\mathrm{F}_{\text {st }}$. Por encima y por debajo de la diagonal principal se muestran los valores de p para pares de microsatélites diferentes. *Diferencia significativa $(\mathrm{p}=0.05)$. $\mathrm{N}=$ no se obtuvo el correspondiente valor por tamaño muestral muy pequeño.

- The matrix values belong to the probability $(\mathrm{p})$ obtained throughtout the $\mathrm{F}_{\mathrm{st}}$ statistic. The values above and below of the main matrix diagonal are $\mathrm{p}$ for two different microsatellites. *Significant differences $(\mathrm{p}=0.05)$. $\mathrm{N}=$ the value was not calculated since the sample sizes were very low.

Lo mismo ocurre para el marcador Cervid 3 $(p=0.0039)$, donde todos los pares de especies difieren con significación estadística. Idéntico hecho se constató al comparar simultáneamente todos los loci analizados para las tres especies de Mazama $(\mathrm{p}=0.0050)$. En el seno de $M$. americana, se detectó heterogeneidad genética significativa para Cervid 1 entre la población del departamento de Córdoba (Norte de Colombia) y la de Leticia (Amazonia Colombiana) y entre la primera y la población de Loreto en la Amazonía peruana $(\mathrm{p}=0.01198$ y $\mathrm{p}=0.0131$, respectivamente $)$, al igual que para la comparación simultánea de todas las poblaciones estudiadas de $M$. americana $(\mathrm{p}=0.0057)$. Similar circunstancia se encontró para Cervid 3 entre la población de Córdoba y la de Loreto (Perú) $(\mathrm{p}=0.01548)$ y para el conjunto analizado de todas las poblaciones de esta especie $(\mathrm{p}=0.0349)$. Por el contrario, no se detectaron diferencias significativas para los loci IDVGA 55, BOVIRBP o NVHRT73, por citar algunos ejemplos. En el caso de $M$. gouzaoubira, se determinaron 
CUADRO 9

Flujo Génico (Nm) entre algunas poblaciones de cérvidos neotropicales respecto a diferentes escalas geográficas consideradas

TABLE 9

Gene flow (Nm) among several Neotropical deer populations taken different geographic scales

\begin{tabular}{lcr}
\multicolumn{1}{c}{ Especie } & Poblaciones & Nm \\
Mazama sp. & Por países & 0.6005 \\
Mazama sp. & Por especies & 0.6511 \\
Mazama americana & Por Regiones & 0.8578 \\
Mazama gouazoubira & Por Regiones & 0.3800 \\
Odocoileus virginianus & Por países & 0.3593 \\
Odocoileus virginianus & Por Regiones Colombianas & 1.4388
\end{tabular}

diferencias entre las poblaciones de Bolivia y Venezuela ( $\mathrm{p}=0.0251$; Cervid 3 ) y para el conjunto global de poblaciones de esta especie para ese mismo marcador $(\mathrm{p}=0.0005)$. En el caso de Odocoileus virginianus, se observó una conspicua diferenciación del conjunto de animales colombianos respecto a las muestras de las restantes poblaciones analizadas para los marcadores Cervid 3 ( $\mathrm{p}=0.0055)$, IDVGA $55(\mathrm{p}=0.0238)$ y NVHRT $16(\mathrm{p}=0.04)$ y para el conjunto total de microsatélites estudiados $(\mathrm{p}=0.0005)$. De modo más particularizado, la muestra colombiana y la venezolana fueron significativamente diferentes para IDVGA 55 $(\mathrm{p}=0.02378)$ y Cervid $3(\mathrm{p}=0.0056)$. En el interior de Colombia, se analizaron dos poblaciones de $O$. virginianus, que representan las cordilleras andinas central y oriental, no encontrándose ningún caso de heterogeneidad genética significativa para ninguno de los loci analizados. Resulta evidente que el marcador que mejor ayuda a discriminar poblaciones en el seno de esos dos géneros de ciervos neotropicales fue Cervid 3, por lo que se recomienda su uso para el análisis poblacional de esos taxones.

Cuando se estimó el flujo génico entre las diferentes agrupaciones de Mazama sp., M. americana y de $M$. gouzaoubira, los valores obtenidos fueron muy bajos $(\mathrm{Nm}=0.38-0.85)$. Igualmente, la estima de flujo génico entre las poblaciones de Odocoileus virginianus por países fue extremadamente baja $(\mathrm{Nm}=0.36)$. $\mathrm{La}$ única estima ligeramente elevada fue la que se encontró entre las dos poblaciones colombianas de esta especie (Cordillera central vs. Cordillera oriental) $(\mathrm{Nm}=1.44)$. Todo ello implica que el manejo conservacionista de las poblaciones de Mazama y de Odocoileus tiene que tener muy presente la elevada heterogeneidad genética, y el débil flujo génico, que parece ocurrir entre poblaciones de esos dos géneros de cérvidos neotropicales.

Detección de cuellos de botella en cérvidos neotropicales: El análisis de la detección de posibles cuellos de botella recientes para las diferentes especies y poblaciones estudiadas de cérvidos neotropicales, a partir de la teoría de Luikart et al. (1998), no detectó evidencias fehacientes de la existencia de cuellos de botella para los taxones analizados con los loci microsatélites empleados (Cuadro 10). Los únicos casos que se aproximaron a esa situación fueron el de Odocoileus virginianus, para el conjunto global de muestras, mediante el test de Wilcoxon y para el modelo mutacional de los alelos infinitos ( $\mathrm{p}=0.0156)$, el de $O$. virginianus a nivel de Colombia para el marcador IDVGA 55 para ambos modelos mutacionales, alelos infinitos y "step-wise" ( $\mathrm{p}=0.0060$ y $\mathrm{p}=0.0160$, respectivamente) y para Hippocamelus antisensis, en el caso de Cervid 1 ( $\mathrm{p}=0.0458)$. No obstante, no se puede enfatizar la detección clara y conspicua de cuellos de botella recientes en las especies de ciervos neotropicales estudiados. 
CUADRO 10

Determinación de cuellos de botella recientes en diversos taxones y poblaciones de cérvidos neotropicales

TABLE 10

Recent Bottleneck event determination in Neotropical deer populations

\begin{tabular}{lllccc}
\multirow{2}{*}{ Especie } & \multicolumn{1}{c}{ Localidad } & \multicolumn{2}{c}{ Test estandarizado } & \multicolumn{2}{c}{ Test Wilcoxon } \\
& Total & IAM & SMM & IAM & SMM \\
O. virginianus & Colombia & 0.1240 & 0.2553 & $\mathbf{0 . 0 1 5 6}$ & 0.6875 \\
& Andes centrales & 0.1616 & 0.4290 & 0.0781 & 0.8906 \\
& Andes orientales & 0.0547 & 0.1807 & 1.0000 & 1.0000 \\
& Total & 0.1406 & 0.4412 & 1.0000 & 0.9062 \\
Mazama sp. & Total & 0.3267 & $\mathbf{0 . 0 2 7 6}$ & 0.4688 & 0.0547 \\
M. americana & Bolivia & 0.3577 & 0.2468 & 0.9062 & 0.0938 \\
& Colombia & 0.2304 & 0.2312 & 1.0000 & 1.0000 \\
& Córdoba & 0.2775 & 0.1005 & 0.2500 & 0.2500 \\
& Leticia & 0.1876 & 0.0922 & 0.1250 & 0.1250 \\
M. gouazoubira & Perú & 0.2742 & 0.2590 & 0.2500 & 0.2500 \\
& Total & 0.4498 & 0.2566 & 0.1875 & 0.1875 \\
& Guyana & 0.3061 & 0.4305 & 0.8750 & 0.8750 \\
M. rufina & Venezuela & 0.2627 & & 0.2500 & 0.8750 \\
H. antisensis & Bolivia & 0.2310 & 0.2927 & 0.8750 & 1.0000 \\
& Total & 0.4215 & & 0.8750 & 0.6250 \\
& Total & 0.0567 & 0.0838 & 1.0000 & 0.8750
\end{tabular}

- IAM=Modelo mutacional de alelos infinitos. SMM=Modelo mutacional "step-wise". En negrilla, las probabilidades significativas.

- IAM=Infinite allele mutation model. SMM=Mutation step-wise model. In bold, significant probabilities.

Es posible que el tamaño de las muestras y el número de marcadores se deban ampliar para aumentar el poder estadístico de las técnicas usadas en la detección de cuellos de botella.

\section{DISCUSIÓN}

Cabe resaltar que, con certeza, sólo se observó la no amplificación de Cervid 1 y RM012 para los individuos de las especies del género Capreolus y de Cervid 1 y Cervid 3 en $C$. elaphus y $C$. nippon. Esto demuestra que existe una considerable cantidad de loci microsatélites conservados en especies y taxones diferentes de Artiodactyla, al igual que ocurre en otros grupos de mamíferos (Gortari et al. 1997; Slate et al. 1998; Ruiz-García 2005;
Ruiz-García \& Alvarez 2003; Ruiz-García et al. 2006). La mayor cantidad de resultados se obtuvieron para Odocoileus virginianus y Mazama americana. Esto no sólo se debe a la mayor cantidad de muestras analizadas de esas especies, sino al alto polimorfismo encontrado en, y entre, las diferentes regiones geográficas de procedencia de esas muestras. Adicionalmente, los ejemplares de Mazama gouazoubira presentaron el más alto grado de polimorfismo y diversidad genética con los microsatélites empleados, aun cuando el tamaño muestral obtenido y el número estudiado de poblaciones fue considerablemente menor que en las dos especies precedentes.

Tal como se preveía, las muestras de $C$. elaphus de Escocia, una población conformada 
por la introducción de ejemplares de diversas subespecies, es la que presentó una variabilidad genética más conspicua. Igualmente, y tal como era previsible, la especie que presentó menor variabilidad genética fue la población de C. nippon escocesa, mostrando un fuerte efecto fundador durante su formación a mediados del siglo XIX, o principio del siglo XX. Las restantes especies de cérvidos europeos y neotropicales presentaron diversidades genéticas intermedias entre esos dos valores extremos. De este modo, no parece que las especies analizadas de cérvidos neotropicales en este estudio estén afectadas por una especial depauperación genética, la cual es característica de poblaciones con tamaños poblacionales efectivos muy reducidos. Igualmente, la mayor parte de las especies analizadas tuvieron valores promedios de heterocigosis más elevados que una buena fracción de las poblaciones de tamaño considerable de C. nippon en Japón (Goodman et al. 2001). En consonancia con esta afirmación, no se detectó ningún cuello de botella genético evidente en los diversos taxones de cérvidos neotropicales analizados, al utilizar los métodos de Cornuet \& Luikart (1996) y Luikart et al. (1998). La única excepción fue la de Mazama rufina con una variabilidad genética considerablemente reducida $(\mathrm{H}=0.125)$. Sin embargo, el tamaño muestral utilizado para esta especie fue extremadamente pequeño $(\mathrm{n}=2)$. En general, utilizando otros marcadores moleculares, en los pocos estudios realizados con ciervos neotropicales, se han encontrado niveles de variabilidad genética muy diversos. González et al. (1998), estudiando 453 pares de bases (pb) para la región de control del ADN mitocondrial de 54 ejemplares de Ozotoceros bezoarticus procedentes de séis localidades diferentes, encontraron niveles de diversidad genética extremadamente elevados (45 haplotipos con ninguna localidad compartiendo haplotipos; diversidad haplotípica $=0.99$ y $\pi$ (diversidad nucleotídica) $=0.011-0.025$ ). Moscarella et al. (2003), analizando $730 \mathrm{pb}$ de la región de control en 26 individuos representando las tres subespecies de Odocoileus virginianus en Venezuela (O. v. gymnotis, O. v. goudotti, $O$. v. margaritae), mostraron niveles moderados de diversidad genética. Los niveles de diversidad haplotípica fueron muy elevados para la muestra total $(0.988)$ y para las tres subespecies (0.967, 1, 1, respectivamente), siendo esos valores notablemente superiores a los encontrados en poblaciones norteamericanas de $O$. virginianus (Ellsworth et al. 1994; Purdue et al. 2000). Sin embargo, los niveles de $\pi$ fueron muy heterogéneos. El valor de $O$. v. gymnotis (0.029) es elevado, el de $O$. v. margaritae (0.016) es medio y el de $O$. goudotti (0.005) es bajo. El resultado obtenido para esta última subespecie es muy similar al encontrado para Muntiacus crinifrons, cérvido del sudeste asiático. Wu \& Fang (2005), analizando también la región de control mitocondrial, encontraron nueve haplotipos en 44 ejemplares de esta especie con pequeños números efectivos históricos con un valor de $\pi=0.00562$ muy pequeño, pero con una diversidad haplotípica considerable (0.862). Márquez et al. (2006), estudiando $601 \mathrm{pb}$ de la región de control mitocondrial y $486 \mathrm{pb}$ del citocromo-b mitocondrial en 127 especimenes de Blastocerus dichotomus de cuatro áreas de la cuenca del río de La Plata, determinaron 17 haplotipos para la región de control en Brasil, Argentina y Bolivia pero, esos haplotipos únicamente difirieron por 1-8 substituciones nucleotídicas, mientras que con citocromo-b encontraron solo tres sitios variables que determinaron cuatro haplotipos. Igualmente, la diversidad haplotípica estimada para la muestra global (0.64) y para todas las muestras brasileñas (0.57) fue modesta, siendo $\pi$, especialmente, bajo para esas dos muestras (0.0017 y 0.0012 , respectivamente). En idéntica circunstancia, no se descubrió variación cariotípica (Duarte \& Giannoni 1995) en esta especie.

Por otra parte, la heterocigosis esperada (H) obtenida con los microsatélites resultó considerablemente mayor que los valores obtenidos con isoenzimas y proteínas plasmáticas, como era de esperarse. Algunos ejemplos con cérvidos son los siguientes: Cervus elaphus atlanticus, $\mathrm{H}=0$, C. e. scoticus, $\mathrm{H}=0.03$, con 35 loci isoenzimáticos (Gyllensten et al. 
1983); Mazama americana, $\mathrm{H}=0.070$, M. gouazoubira, $\mathrm{H}=0.079$, Odocoileus virginianus del suroeste de Estados Unidos y de Surinam, $\mathrm{H}=0.078$ y 0.036 , respectivamente (Smith et al. 1986); poblaciones norteamericanas de $C$. elaphus, $\mathrm{H}=0.012-0.034$, utilizando 16 loci isoenzimáticos (Glenn \& Smith 1993); poblaciones híbridas entre $C$. elaphus y $C$. nippon, para 15 marcadores, $\mathrm{H}=0.051$ y 0.033 (Herzog et al. 1991); Dama dama, en Inglaterra y Gales para 30 loci, H=0 (Pemberton \& Smith 1985); Odocoileus virginianus, para ocho poblaciones y 35 loci, $\mathrm{H}=0.049-0.092$ (Smith et al. 1985); Alces alces, 18 poblaciones estudiadas en Escandinavia para 23 loci, $\mathrm{H}=0.006-0.047$ (Ryman et al. 1980). Oliveira et al. (2005) analizaron 147 individuos de Blastocerus dichotomus procedentes de tres áreas del río Paraná con 17 loci isoenzimáticos. Once de esos loci resultaron monomórficos, siendo los seis restantes polimórficos (polimorfismo del $35.29 \%$ ) con $\mathrm{H}=0.0631$ y el número promedio de alelos por locus de $1.47 \pm 0.45$. Recordemos algunos de los valores de $\mathrm{H}$ obtenidos en el presente trabajo con loci microsatélites: C. elaphus en Escocia, $\mathrm{H}=0.81$; C. elaphus en Italia, $\mathrm{H}=0.56$; Odocoileus virginianus en Colombia, $\mathrm{H}=0.62$, Dama dama en España, H=0.73, Mazama gouzaoubira, $\mathrm{H}=0.70$ o Blastocerus dichotomus, $\tan$ solo con 8 individuos, $\mathrm{H}=0.36$.

Con los resultados obtenidos para la estima del equilibrio Hardy-Weinberg deben hacerse dos anotaciones. La primera de ellas es que las poblaciones que no se encontraron en equilibrio (Mazama y Odocoileus, especialmente) recogían individuos de diferentes localidades geográficas en diferentes puntos de Latinoamérica. De este modo, la ausencia de equilibrio Hardy-Weinberg por exceso de homocigotos puede estar promovida por efecto Wahlund (= subdivisión). Esto es, por efecto de subdivisión geográfica debido a la existencia de acervos genéticos bien diferenciados en el seno de esas especies y géneros en diversos países latinoamericanos. Un caso excepcional se dio para la muestra de Mazama americana procedentes de la región de Loreto, Amazonía peruana. Todos los individuos analizados pertenecieron a una misma región geográfica relativamente pequeña. La falta de equilibrio podría explicarse, en ese caso, por la existencia de consanguinidad en el seno de esa población o por la existencia en simpatría de dos especies de Mazama, similares morfológicamente, pero todavía no determinadas taxonómicamente. Esto ya ha sido reportado por otros autores para otros grupos de Mazama (Duarte \& Merino 1997). Estos autores mostraron que dos especies de Mazama, aparentemente idénticas desde el punto de vista morfológico, poseían cariotipos diferentes.

El análisis de heterogeneidad genética $\left(\mathrm{F}_{\mathrm{ST}}\right)$ mostró poblaciones del género Mazama fuertemente diferenciadas para los loci Cervid 1 y Cervid 3. La importancia de este hecho reside en la utilidad de estos marcadores para diferenciar ejemplares de diversas procedencias, lo que es de mucha utilidad cuando no se posee la certeza del origen geográfico de los ejemplares, como es el caso de individuos decomisados. Por otro lado, es apreciable que el flujo genético entre las poblaciones de Mazama es muy reducido, siendo apenas moderado entre las poblaciones de Odocoileus virginianus que se encuentran en la cordillera central y oriental de los Andes colombianos. Por lo tanto, resulta evidente una fuerte heterogeneidad genética entre las diversas especies de Mazama y en el interior de M. americana. Esto es equiparable a lo encontrado en otras especies de ciervos neotropicales con otros marcadores moleculares. González et al. (1998) estimaron una fuerte heterogeneidad genética entre 6 poblaciones de Ozotoceros bezoarticus distribuidas por Brasil, Uruguay y Argentina $\left(\phi_{\mathrm{ST}}=0.268-0.523\right.$ con promedio $0.37, \mathrm{p}<0.002)$. Únicamente, dos poblaciones argentinas de esta especie no alcanzaron a mostrar heterogeneidad significativa entre ellas $\left(\phi_{\mathrm{ST}}=0.064, \mathrm{p}=0.17\right)$. La estima de flujo génico entre estas dos poblaciones fue elevada $(\mathrm{Nm}=7.1)$. Sin embargo, la estima promedio de flujo génico entre todas las poblaciones a partir del estadístico $\phi_{\mathrm{ST}} \mathrm{y}$ a partir del método de Slatkin \& Maddison (1989) (0.87 y 0.5$)$ muestran el fuerte aislamiento genético entre esas poblaciones de este ciervo. 
El aislamiento por distancia (clina norte-sur) parece contribuir a la heterogeneidad genética encontrada $(r=0.6, p=0.014)$. La fuerte diferenciación genética que se encuentra en la población de Mazama americana del área amazónica de Loreto en Perú es similar a lo encontrado en Ozotoceros bezoarticus. En el interior de las poblaciones brasileñas de esta especie los haplotipos divergieron entre el $0.4 \%$ al $5.5 \%$, mientras que en el interior de la poblaciones uruguayas, esos valores oscilaron entre el $0.2 \%$ al 5.5\%. También, la heterogeneidad genética entre poblaciones de Blastocerus dichotomus de la cuenca del río de La Plata (Márquez et al. 2006) resultó altamente significativa tanto entre regiones $\left(\phi_{\mathrm{CT}}=0.56, \mathrm{p}=0.02\right)$ como entre poblaciones dentro de las regiones $\left(\phi_{\mathrm{SC}}=0.25\right.$, $\mathrm{p}=0.00$ ), aunque, también, lo fue dentro de las poblaciones $\left(\phi_{\mathrm{ST}}=0.67, \mathrm{p}=0.00\right)$. De nuevo, el aislamiento por distancia explicó una proporción importante de las diferencias genéticas entre las poblaciones estudiadas $(\mathrm{r}=0.792$, $\mathrm{p}$ $<0.05$ ). No obstante, entre tres poblaciones de esta especie en la cuenca del río Paraná, la heterogeneidad fue mucho más moderada $\left(\mathrm{F}_{\mathrm{ST}}\right.$ $=0.049 ; \mathrm{Nm}=4.9)$ y las distancias genéticas entre esas poblaciones fueron pequeñas (0.0140.051) (Oliveira et al. 2005). También es destacable la heterogeneidad genética significativa entre todas las poblaciones de $O$. virginianus estudiadas aquí en diversos países y entre las poblaciones de $O$. virginianus de Colombia y Venezuela. Este resultado es concordante con la heterogeneidad genética que presenta esta especie, por ejemplo, en Venezuela (Moscarella et al. 2003). Entre todas las poblaciones venezolanas estudiadas, la heterogeneidad resultó altamente significativa $\left(\phi_{\mathrm{ST}}=0.27, \mathrm{p}<0.0001\right)$, aunque, especialmente, entre $O$. v. goudotti (población andina) y $O . v$. margaritae (población insular caribeña) $\left(\phi_{\mathrm{ST}}=0.615\right)$. En este estudio se detectaron cuatro linajes genéticos diferentes. En el primero se detectaron los haplotipos de $O$. v. goudotti junto con cinco haplotipos de O. v. gymnotis; en el segundo los haplotipos de $O$. v. margaritae y un haplotipo de $O$. v. gymnotis procedente de Sucre, área geográfica cercana a la isla Margarita; en el tercero, se agruparon haplotipos de ejemplares procedentes del área de los Llanos y en el cuarto linaje, se encontraron haplotipos de animales procedentes de la costa de ese país. Esto mostró la inexistencia de monofilia en el seno de $O$. v. gymnotis. No es de extrañar, pues, la heterogeneidad genética encontrada en el presente estudio al utilizar microsatélites entre diversas poblaciones de $O$. virginianus. De hecho, la heterogeneidad genética encontrada entre secuencias mitocondriales de $O$. virginianus ha mostrado que existe más diferenciación genética entre los haplotipos de poblaciones sudamericanas de esta especie respecto a poblaciones norteamericanas de la misma especie que entre la última y $O$. hemionus de Norteamérica (Moscarella et al. 2003), aunque, en ocasiones, se encuentran algunos animales en Sudamérica más similares a los norteamericanos que a otros ejemplares sudamericanos (Ruiz-García et al. 2007). A nivel morfológico, se han reconocido, al menos, 30 subespecies de $O$. virginianus en Norte y Centro América y ocho subespecies en Sudamérica (Baker 1984; Smith 1991) lo que ratifica la enorme diversidad de esta especie. Muchos de los procesos que han causado una fuerte heterogeneidad genética entre las poblaciones de cérvidos pueden estar relacionadas con cambios climáticos originados en el Pleistoceno superior. Por ejemplo, Vernesi et al. (2002) mostraron que la alta heterogeneidad genética determinada para Capreolus capreolus en Europa $\left(\phi_{\mathrm{ST}}=0.60\right)$, reflejada entre tres grupos genéticamente bien diferenciados (Italia central, el grupo alpino relacionado con poblaciones de Francia, España y Noruega, y las poblaciones del este de Europa) se formaron en tres refugios diferentes del sur de Europa durante el Pleistoceno superior.

Mediante la teoría de Cornuet \& Luikart (1996) y Luikart et al. (1998) se estimó la posible existencia de cuellos de botella recientes en las poblaciones neotropicales de ciervos analizadas, obteniéndose resultados no significativos en todos los casos. Debe aclararse que para algunas de estas especies, como Ozotoceros bezoarticus, Pudu mephistopheles y Mazama rufina, el pequeño número de 
ejemplares analizados no permite hacer una interpretación en este aspecto suficientemente adecuada, por lo cual es recomendable realizar un muestreo más intensivo para esos taxones. Sabemos que las poblaciones de Ozotoceros bezoarticus aunque, actualmente, no superan los 60.000-80.000 individuos, esas poblaciones constaron de millones de individuos debido a la elevada diversidad genética que posee esa especie actualmente (González et al. 1998). Eso significa que la reducción demográfica es un evento muy reciente que todavía no ha tenido repercusión en los niveles de variabilidad genética de esa especie. Algo similar ha sido reportado para otras especies de cérvidos. Por ejemplo, Balakrishnan et al. (2003) determinaron, en tres subespecies de Cervus eldi del sudeste asiático (C. eldi eldi, C. e. thamin, C. e. siamensis) en estado crítico, sus correspondientes diversidades genéticas a partir de $478 \mathrm{pb}$ de la región de control mitocondrial. Dos de ellas todavía muestran una muy elevada diversidad (C. e. thamin: $\mathrm{h}=0.82, \pi=0.024$ y C. e. siamensis: $\mathrm{h}=0.81, \pi=0.014)$, lo que refleja que, en el pasado, esas poblaciones contaban millones de individuos reproductores y que las poblaciones se han reducido muy recientemente. En el caso de la tercera subespecie, el cuello de botella ha sido tan brutal que no muestra variación haplotípica. En el caso de Blastocerus dichotomus del Pantanal brasileño parece que experimentó una expansión poblacional hace entre $25000 \mathrm{y}$ 28000 años.

La utilización de loci microsatélites para poder determinar la estructura genética de cérvidos neotropicales, al igual que la secuenciación de genes mitocondriales, y un muestreo más intensivo de esas especies es decisivo para tener un conocimiento preciso y exacto de la historia natural de las mismas y, por lo tanto, la posibilidad de poder manejarlas correctamente desde la perspectiva de la biologia de la conservación.

\section{AGRADECIMIENTOS}

Los autores agradecemos enfáticamente a todas aquellas personas que ayudaron en la tarea de obtener muestras biológicas de cérvidos neotropicales. Entre ellas cabe destacar a Hugo Gálvez de Iquitos (Perú) y a Andrés Eloy Bracho de Maracaibo (Venezuela). También se agradece la obtención de muestras por parte de Armando Castellanos (Ecuador), Francois Catzeflis (Francia) y Jordi Jordana (España). Las comunidades indígenas Yaguas, Ticunas y Huitoto de la Amazonía Colombiana y a las comunidades indígenas Bora, Ocaina, ShipigoComibo, Capanahua, Angoteros, Orejón, Cocama, Kishuarana y Alama en la Amazonía Peruana también colaboraron en la obtención de muestras. Igualmente, se reconoce la ayuda ofrecida por Héctor Corredor (Argentina) al hacernos llegar muestras de Hippocamelus antisensis, recogidas en campo. Se agradece especialmente la ayuda prestada por K. Roed (Noruega) por el envío de cebadores de microsatélites diseñados para Rangifer tarandus que fueron aplicados en ciervos neotropicales. A la Pontificia Universidad Javeriana agradecemos los apoyos prestados por la Decanatura de la Facultad de Ciencias y por la Vicerrectoría Académica por financiar parcialmente un viaje a Bolivia, en 1997, donde se obtuvieron algunas de las muestras.

\section{RESUMEN}

Los programas de conservación de especies se apoyan fuertemente en estudios de genética poblacional. En el presente estudio, reportamos diversos análisis genéticopoblacionales en ocho especies de cérvidos neotropicales (Mazama americana, M. gouzaoubira, M. rufina, Odocoileus virginianus, Hippocamelus antisensis, Pudu mephistopholes, Ozotoceros bezoarticus y Blastoceros dichotomus) $\mathrm{y}$, adicionalmente, en varias especies de cérvidos europeos y asiáticos (Cervus elaphus, C. nippon, Capreolus capreolus, C. pygargus and Dama dama). Una de esas especies europeas, la población de Cervus elaphus en Escocia, fue tomada como una población con un grado muy elevado de diversidad genética ya que proviene del 
cruce de diferentes grupos de ciervos rojos procedentes de diversas subespecies de la Europa continental. Desde una perspectiva de una diversidad genética depauperada, se tomó el nivel encontrado en una población de ciervos sika (Cervus nippon) en Escocia, que prácticamente no mostró variabilidad a nivel molecular. Respecto a esos dos casos que consideramos como de elevada y escasa variabilidad genética, encontramos que las poblaciones analizadas de Mazama americana, M. gouzaoubira y Odocoileus virginianus estuvieron cerca del límite máximo encontrado para el ciervo rojo escocés $(\mathrm{H}=0.64,0.70$ y 0.61 , respectivamente), mientras que $M$. rufina mostró el más bajo grado de variabilidad genética de las especies neotropicales, cercano al extremo mínimo presentado por C. nippon. Algunas de las muestras de Mazama y de Odocoileus, tomadas a nivel macrogeográfico, mostraron un exceso de homocigotos debido, probablemente, a la existencia de efecto Wahlund (efecto de subdivisión). Ninguna de las especies analizadas parece haber atravesado un cuello de botella reciente.

Palabras claves: Cérvidos Neotropicales, Mazama, Odocoileus, microsatelites de ADN, genética de poblaciones.

\section{REFERENCIAS}

Baker, R.H. 1984. Origin, classification, and distribution, p. 1-18. En L.K. Halls (ed.). White-tailed deer: ecology and management. Stackpole Books, Harrisburg, Pensilvania, EEUU.

Balakrishnan, C.N.P., S.L. Monfort, A. Gaur, L. Singh \& M.D. Sorenson. 2003. Phylogeography and conservation genetics of Eld's deer (Cervus eldi). Mol. Ecol. 12: $1-10$.

Cornuet, J.M. \& G. Luikart. 1996. Description and power analysis of two tests for detecting recent population bottlenecks from allele frequency data. Genetics 114 2001-2014.

DeWoody J.A., R.L. Honeycutt \& L.C. Skow. 1995. Microsatellite markers in White-Tailed Deer. J. Hered. 86: 317-319.

Duarte, J.M.B. \& M.L. Merino. 1997. Taxonomia e evolucao. En J.M.B. Duarte (ed.). Biologia e conservacao de Cervídeos Sul-americanos: Blastocerus, Ozotoceros e Mazama. Jaboticabal, FUNEP, Jacotibal, Brasil.

Duarte, J.M.B. \& M.L. Giannoni. 1995. Cytogenetic analysis of the mash deer (Blastocerus dichotomus) (Mammalia, Cervidae). Braz. J. Genet. 18: 245-248.

Ellsworth, D.L., R.L. Honeycutt, N.J. Silvy, M.H. Smith, J.W. Bickham \& W.D. Klimstra. 1994. White-tailed deer restoration to the south-eastern United States: evaluating genetic variation. J. Wildl. Manag. 58: 686-697.
Emmerson, B.C. \& M.L. Tate. 1993. Genetic analysis of evolutionary relationships among deer (Subfamily Cervinae). J. Hered. 84: 266-273.

Engel, S.R., R.A. Linn, J.F. Taylor \& S.K. Davis. 1996. Conservation of microsatellite loci across species of artiodactyls: implications for population studies. J. Mammal. 77: 504-518.

Glenn, T.C. \& D.R. Smith. 1993. Genetic variation and subspecific relationships of Michigan elk (Cervus elaphus). J. Mammal. 74: 782-792.

González, S.G., J.E. Maldonado, J.A. Leonard, C. Vila, J. M.B. Duarte, M. Merino, N. Brum-Zorrilla \& R.K. Wayne. 1998. Conservation genetics of the endangered Pampa deer. Mol. Ecol. 7: 47-56.

Goodman, S.J., N.H. Barton, G. Swanson, K. Abernethy \& J.M. Pemberton. 2000. Introgression through rare hybridization: a genetic study of a hybrid zone between red and sika deer (genus Cervus), in Argyll, Scotland. Genetics 152: 355-371.

Goodman, S.J., H.B. Tamate, R. Wilson, J. Nagata, S. Tatsuzama, G.M. Swanson, J.M. Pemberton \& D.R. McCullogh. 2001. Bottlenecks, drift and differentiation: the population structure and demographic history of sika deer (Cervus nippon) in the Japanese archipielago. Mol. Ecol. 10: 1357-1370.

Gortari De, M.J., B.A. Freking \& S.M. Kappes. 1997. Extensive genomic conservation of cattle microsatellite heterozygosity in sheep. Anim. Genet. 28: 274-290.

Groves, C.P. \& P. Grubb. 1987. Relationships of living deer. En C.M. Wemmer (ed.). Biology and management of the Cervidae. Smithsonian Institution Press, Washington DC, EEUU.

Gyllensten, U., N. Ryman, C. Reuterwall \& P. Dracht. 1983. Genetic differentiation in four European subspecies of red deer (Cervus elaphus). Heredity 51: 561-580.

Hartl, G.B., K. Nadlinger, M. Apollonio, G. Markov, F. Klein, G. Lang, S. Findo \& J. Markowski. 1995. Extensive mitochondrial-DNA differentiation among European red deer (Cervus elaphus) populations: implications for conservation and management. Zeitschrift fur Saugetierkunde 60: 41-52.

Herzog, S., C. Mushovel, H. H. Hattermer \& A. Herzog. 1991. Transferrin polymorphism and genetic differentiation in Cervus elaphus L. (European red deer) populations. Heredity 67: 231-239.

Li, C.C. \& D.G. Horvitz. 1953. Some methods of estimating the inbreeding coefficient. Am. J. Hum. Genet. 5: 107-117. 
Lowe, V.P.W. \& A.S. Gardiner. 1974. A re-examination of the subspecies of red deer (Cervus elaphus) with particular reference to the stocks in Britain. J. Zool. 174: 185-201.

Luikart, G., F. Allendorf, B. Sherwin \& J.M. Cornuet. 1998. Distortion of allele frequency distribution provides a test for recent population bottleneck. J. Hered. 86: 319-322.

Márquez, A., J.E. Maldonado, S. González, M.D. Beccaceci, J.E. García \& J.M.B. Duarte. 2006. Phylogeography and Pleistocene demography history of the endangered mash deer (Blastocerus dichotomus) from the Río de la Plata basin. Conservat. Genet. 7: 563-575.

Moscarella, R.A., M. Aguilera \& A. A. Escalante. 2003. Phylogeography, population structure and implication for conservation of white-tailed deer (Odocoileus virginianus) in Venezuela. J. Mammal. 84: 1300-1315.

Nei, M. 1978. Estimation of average heterozygosity and genetic distance from a small number of individuals. Genetics 89: 583-590.

Oliveira, E. J.F., J.E. García, E. P.B. Contel \& J.M.B. Duarte. 2005. Genetic structure of Blastocerus dichotomus population in the Paraná river basin (Brazil) based on protein variability. Biochem. Genet. 43: 211-222

Ohta, T. \& Kimura, M. 1973. A model of mutation appropiated to estimate the number of electrophoretically detectable alleles in a finite population. Genet. Res. 22: 201-204.

Pemberton, J.M. \& R.H. Smith. 1985. Lack of biochemical polymorphism in British fallow deer. Heredity 55 199-207.

Piry, S., G. Luikart \& J.M. Cornuet. 1999. BOTTLENECK: a computer program for detecting recent reductions in the effective population size using allele frequency data. J. Hered. 90: 502-503.

Powerscourt, V. 1884. On the acclimatization of the Japanese deer at Powerscourt. Proc. Zool. Soc. Lon. 1884: 207-209.

Purdue, J.R., M.H. Smith \& J. C. Patton. 2000. Female philopatry and extreme spatial genetic heterogeneity in white-tailed deer. J. Mammal. 81: 179-185.

Raymond M. \& F. Rousset. 1995. GENEPOP (version 1.2): Population genetics software for exact test and ecumenicism. J. Hered. 86: 248-249.

Robertson, A. \& W. Hill. 1984. Deviations from HardyWeinberg proportions, sampling variances and use in estimation of inbreeding coefficients. Genetics 107: 703-718.

Roed K.H. \& L. Midthjell. 1998. Microsatellites in reindeer, Rangifer tarandus, and their use in other cervids. Mol. Ecol. 7: 1773-1776.

Ruiz-García, M. 1991. Más sobre la genética de poblaciones de Felis catus en la costa Mediterránea española: un análisis de la estructura genética de las poblaciones naturales de gatos. Evolución Biológica 5: $227-283$.

Ruiz-García, M. 2001. Estrategias de Análisis genético poblacionales y filogenéticos utilizando marcadores bioquímicos y moleculares (Alozimas, mtDNA y microsatélites) aplicados a la conservación de mamíferos silvestres. Capítulo 1, p. 5-46. En C. H.. Moreno Durán (ed.). Polimorfismos aplicados en enfermedades metabólicas y evolución. Universidad Distrital Francisco José de Caldas, Bogotá, Colombia.

Ruiz-García, M. \& D. Alvarez. 2003. ¿Pueden los marcadores microsatélites de ADN nuclear reconstruir adecuadamente la filogenia de los primates neotropicales?. Capítulo 3, p. 47-70. En F. Nassar, V. Pereira \& A. Savage (eds.). Primatología del Nuevo Mundo: Biología, Medicina, Manejo, Conservación. Bogotá, Colombia.

Ruiz-García, M. 2005. The use of several microsatellite loci applied to 13 Neotropical primates revealed a strong recent bottleneck event in the woolly monkey (Lagothrix lagotricha) in Colombia. Primate Report 71: 27-55.

Ruiz-García, M., C.E. Payan, A. Murillo \& D. Alvarez. 2006. DNA Microsatellite characterization of the jaguar (Panthera onca) in Colombia. Gen. Genet. Syst. 81:115-127.

Ruiz-García, M., E. Randi, M. Martínez-Agüero \& D. Alvarez. 2007. Relaciones filogenéticas entre géneros de ciervos neotropicales (Artiodactyla: Cervidae) mediante secuenciación de ADN mitocondrial y marcadores microsatélitales. Rev. Biol. Trop. 55: 723-741.

Ryman, N., G. Beckman, G. Braun-Peterson, \& T. Nygren. 1980. Genetic variation and differentiation in Scandinavian moose (Alces alces): are large mammals monomorphic ?. Evolution 34: 1037-1049.

Slate, J., D.W. Coltman, S.J. Goodman, I. Maclean, J.M. Pemberton \& J. L. Williams. 1998. Bovine microsatellite loci are highly conserved in red deer (Cervus elaphus), sika deer (Cervus nippon) and Soay sheep (Ovis aries). Anim. Genet. 28: 307-315.

Slatkin, M. 1985. Rare alleles as indicators of gene flow. Evolution 39: 53-65. 
Slatkin, M. \& W.P. Maddison. 1989. A cladistic measure of gene inferred from the phylogenies of alleles. Genetics 123: 603-613.

Smith, W.P. 1991. Odocoileus virginianus. Mammalian Species 388: 1-13.

Smith, M.H., R. Baccus, H.O. Hillestad \& M.N. Manlove. 1985. Population genetics of the white-tailed deer. En L. Halls (ed.). White-tailed deer, ecology, and management. Wildlife Management Institute, Washington DC., EEUU.

Smith, M.H., W.V. Branan, R.L. Marchinton, P.E. Johns \& M. Wooten. 1986. Genetic and morphologic comparisons of red brocket, brown brocket, and white-tailed deer. J. Mammal. 67: 106-111.

Vernesi, C., E. Pecchicli, D. Caramelli, R. Tiedemann, E. Randi \& G. Bertorelle. 2002. The genetic structure of natural and reintroduced roe deer (Capreoulus capreolus) populations in the Alps and Central Italy, with reference to the mitochondrial DNA phylogeography of Europe. Mol. Ecol. 11: 1285-1297.

Weir, B.S. \& C.C. Cockerham. 1984. Estimating F-statistics for the analysis of population structure. Evolution 38: $1358-1370$

Whitehead, G.K. 1972. Deer of the world. Constable. Londres, Inglaterra.

Wright, S. 1965. The interpretation of population structure by F-statistics with special regards to systems of mating. Evolution 19: 395-420.

Wu, H-L. \& S-G. Fang. 2005. Mitochondrial DNA genetic diversity of black Muntjac (Muntiacus crinifrons), an endangered species endemic to China. Biochem. Genet. 43: 407-416.

\section{ANEXO I}

Número de alelos y rango de tamaños alélicos detectados previamente para diversos loci microsatélites (RM012, BM757, IDVGA055, FCB193, TGLA337, HUJ175, BOVIRBP, TGLA127 y FSHB) en Cervus nippon y C. elaphus. Adicionalmente se muestra la temperatura de anillamiento para la PCR de cada marcador.

Previously detected allele numbers and size allele range for diverse DNA microsatellite loci analyzed (RM012, BM757, IDVGA055, FCB193, TGLA337, HUJ175, BOVIRBP, TGLA127 and FSHB) in Cervus nippon and C. elaphus. In addition, the annelling temperature for the PCR of each marker is shown.

\begin{tabular}{lccccc}
\multicolumn{1}{c}{ Locus } & $\begin{array}{c}\text { \# alelos } \\
\text { Cervus nippon }\end{array}$ & $\begin{array}{c}\text { Rango alelos } \\
\text { Cervus nippon }\end{array}$ & $\begin{array}{c}\text { \# alelos } \\
\text { Cervus elaphus }\end{array}$ & $\begin{array}{c}\text { Rango alelos } \\
\text { Cervus elaphus }\end{array}$ & $\begin{array}{c}\text { Temperatura } \\
\text { anillamiento }\end{array}$ \\
RM012 & 1 & 115 & 12 & $>=123$ & $53-55$ \\
BM757 & 2 & 175,177 & $12+$ & $163,165,177+$ & $48-50$ \\
INRA131 & 1 & 107 & 6 & $93-105$ & $53-55$ \\
IDVGA055 & 1 & 213 & 5 & $193-201$ & $52-54$ \\
FCB193 & 4 & $123,127,129,139$ & 12 & $97-121$ & $52-54$ \\
TGLA337 & 1 & 128 & 5 & $132+$ & $50-52$ \\
HUJ175 & 1 & 139 & 7 & $155-133,+$ nulo? & $50-52$ \\
BOVIRBP & 3 & $142-146$ & 8 & $148-166$ & $52-54$ \\
TGLA127 & 1 & 157 & $8+$ & $165+$ & $52-54$ \\
FSHB & 1 & 181 & $12+$ & $185+$ & $52-54$
\end{tabular}

